\title{
CHILDREN, SCHOOLS AND FAMILIES BILL
}

\author{
An Equalities Impact Assessment prepared by \\ the Department for Children, Schools and Families \\ and the Ministry of Justice
}

For Introduction into the House of Lords, February 2010 
1. Introduction to the Children, Schools and Families Bill

2. Overall equalities impact assessment 4

3. What the evidence shows

4. Introducing the pupil and parent guarantees 12

5. Home School Agreements 20

6. Parental responsiveness 28

7. Alternative Provision 33

8. Special Educational Needs (SEN) \& right to appeal 38

9. Power to provide community facilities 42

10. Powers of governing bodies $\quad 45$

11. School Improvement Partners $\quad 48$

12. Data collection (School Report Card) 51

13. Data collection (Wales)

14. Intervention and accredited groups $\quad 59$

15. SEN \& inspection $\quad 65$

$\begin{array}{ll}\text { 16. Primary curriculum } & 67\end{array}$

17.Personal, Social, Health and Economic (PSHE) Education 70

18. Licence to Practise $\quad 72$

19. Elective Home Education $\quad 75$

20. Intervening in failing Youth Offending Teams 79

21. Family Courts $\quad 85$

$\begin{array}{ll}\text { 22. Relevant Literature } & 91\end{array}$ 


\section{The Children, Schools and Families Bill}

Following extensive consultation and research, the Children, Schools and Families Bill will reform schools and wider children's services through providing guarantees for parents and pupils setting out what they can expect from a $21^{\text {st }}$ century schools system. These will equip every child, every family and everyone who works with them to meet the challenges ahead, and so help secure this country's success now and in the future. It builds on a decade of ever-increasing standards of pupil achievement, record investment in infrastructure and the workforce, and the development of one of the most robust children's safeguarding system in the world. It will take all these areas to the next stage - so that every child has a great start in life and is assured every chance of success in the future.

Guarantees - through new pupil and parent guarantees the Government is committing for the first time to a series of specific entitlements for all, and providing a means of redress if expectations are not met.

21st century schools - building on over a decade of increasing school standards, this Bill will deliver the building blocks for a world class 21st century schooling system that meets the needs of every pupil so they can achieve their full potential.

Curriculum reforms - learning from wide ranging consultation and international evidence, the Bill will introduce reforms to the school curriculum so children and young people are equipped with the knowledge and skills they, and future employers, want and need.

Licence to practise - improving teaching underpins every effort to achieve the best possible education for all pupils, and through a new licensing system this Bill will help to professionalise the workforce. We will also ensure the workforce is supported to deliver the quality of teaching they deserve.

Safeguarding the vulnerable - strengthening the powers of local authorities and others with regards to registration, monitoring and intervention will mean effective systems are in place to protect those that most need it.

Increasing public confidence in family courts - opening up the family courts by broadening the amount of information which can be reported by the media.

The Children, Schools and Families Bill was Introduced to the House of Commons on 18 November 2009, and an Equalities Impact Assessment was published at that time. This version has been updated to take account of changes as a result of the Bill's passage through the Commons, and policy developments between November 2009 and February 2010. 


\section{Summary Equalities Impact Assessment}

Overall a positive impact is explicitly intended and very likely.

Each of the policies included in the Children, Schools and Families Bill underwent initial screening to establish whether they were likely to have any significant effect - either positive or negative - on the Government's drive to improve disability, ethnicity and gender equality.

Where it was established that there may be an effect, whether positive or negative, an individual Equalities Impact Assessment was carried out. This involved analysis of relevant evidence, and where appropriate, further policy work to ensure that any risk of negative impact is mitigated, and any potential positive impact is maximised as far as is practical.

Those assessments highlighted significant benefits, and this document brings the information from each one together, to demonstrate the impact of the Bill as a whole. Much of the evidence considered is relevant to more than one policy area, so to avoid repetition it is all set out together in Chapter 2.

This Bill includes some provisions relating to family courts, which are led by the Ministry of Justice (MoJ), rather than the Department for Children, Schools and Families. Therefore, those provisions are subject to MoJ procedures and, accordingly, that section is set out differently from the rest of the document. 


\section{What the Evidence Shows}

The evidence outlined in this section underpins the development of many of the policies set out in the main body of the Equalities Impact Assessment for the Children, Schools and Families Bill

\section{Disability}

\section{General}

- Eight out of ten children with learning disabilities have been bullied at school and six out of ten have been physically hurt (MENCAP, 2007).

- Disabled children and those with visible medical conditions can be twice as likely as their peers to become targets for bullying behaviour (Office of the Children's Commissioner, 2006).

\section{Employment}

- Disabled people of working age are more than twice as likely as nondisabled people to have no qualifications at all: 25 per cent compared with ten per cent (LFS, autumn 2005). Only 44 per cent of disabled people are economically active compared with 79 per cent of non-disabled people (Disabled for life? Attitudes towards, and experiences of, disability in Britain, Report by DWP).

\section{Education}

- Disabled pupils are frequently excluded from certain subjects, faced with low expectations and assumptions and often not given genuine choices (Disability rights commission 2005).

- Disabled pupils experience inconsistencies in the provision of support and curriculum resources. For example, good deployment of teaching assistants can be the critical factor in inclusive learning, but can equally distance pupils from teaching and learning (Disability Rights Commission published a literature review, 2005).

- There is a low awareness of making reasonable adjustments amongst staff and governors (Disability Rights Commission published a literature review, 2005).

- At age 16, 68 per cent of disabled young people are in full time education, compared with 72 per cent of those who are not disabled (YCS SFR04/2005).

- At the age of 16,15 per cent of disabled young people are not in education, employment or training (NEET) compared with seven per cent of those who are not disabled (YCS SFR04/2005).

- In 2005 , by the age of 19 , only 59 per cent of disabled people had reached at least level 2, compared with 77 per cent of those without a disability (YCS SFR 49/2005). 
- In a report by the University of Bath, which even though was a relatively small-scale study, did show $13 \%$ of those parents who returned questionnaires as part of the study indicated that their child met the Disability Discrimination Act criteria. The report confirmed our understanding that disability and special educational needs are not the same thing, and that there are young people in each of the categories separately while also not appearing in the other. It was found that, in general, those pupils who meet the Disability Discrimination Act criteria, but not the special educational needs criteria, are progressing in line with their peers (contextual value added data and progress from Key Stage 1 to Key Stage 2 were analysed for this) (DCSF Research Brief 062).

- One fifth of all pupils in schools have special educational needs and disabilities, and too many do not fulfil or realise their potential. In 2008, less than 12 per cent of pupils with special educational needs achieved five GCSEs at $A^{*}-C$, including English and maths, compared to 57 per cent of their peers (DCSF Statistical First Release18/2009).

- Pupils with SEN perform less well than pupils with no identified SEN in each stage of education (DCSF: Attainment by Pupil Characteristics, in England 2007/08).

- In 2006, 8.5 per cent of pupils with a statement of special educational needs gained five or more GCSE grades $A^{*}-C$, compared with 65.9 per cent of those without such a statement (SFR 46/2006).

- The percentage of pupils with special educational needs achieving level 4 or above in English and maths increased from 28.3 per cent in 2006 to 33.7 per cent in 2008. This was an increase of 5.4 percentage points. Over the same period, the figure for pupils with no special educational needs increased by 3.0 percentage points from 81.6 percent in 2006 to 84.6 per cent in 2008 (Children with special educational needs: an analysis, DCSF 2009).

- $40 \%$ of young people with SEN achieved a Level 2 qualification at age 19 as against $80.7 \%$ of those without SEN (Children with special educational needs: an analysis, DCSF 2009).

\section{Exclusions}

- Pupils with SEN (both with and without statements) are over 8 times more likely to be permanently excluded than those pupils with no SEN. In 2007/08, 33 in every 10,000 pupils with statements of SEN and 38 in every 10,000 pupils with SEN without statements were permanently excluded from school. This compares with 4 in every 10,000 pupils with no SEN (DCSF Statistical First Release18/2009).

- The figures show a small decrease in the rate of fixed period exclusions in secondary schools for those pupils with SEN compared with the previous year. In 2007/08, the rate of fixed period exclusion for those pupils with statements was 30.8 per cent; the rate for those with SEN without statements was 28.9 per cent. This compares to 5.1 per cent for those pupils with no SEN (DCSF Statistical First Release18/2009). 


\section{Ethnicity}

\section{General}

- There are examples of racist incidents in schools. For instance in Leeds the number recorded increased from 1,142 in 2002/3 to 1,430 in 2005/6. Over the same period Birmingham schools saw an increase from 832 to 1,577, and Manchester schools rose from 590 to 696. Other noticeable rises in racist reports occurred in Bolton, Coventry, Derby, Dudley, Kent and Lancashire (Somerset Racial Equality Council Newslink July 2007, quoting research by Channel 4 online).

- With regard to ethnicity and health, social issues such as housing, unemployment, racism, education and literacy can have a substantial impact both on the health of patients and their ability to focus on their specific health needs. Conversely, health issues may add to social problems. For example, Bengali children are sometimes badly nourished and this can lead to underachievement in school, compounding existing inequalities (No Patient Left Behind, Department for Health, 2008).

\section{Education}

- Ethnic origin is a significant indicator of educational performance. At the end of key stage 3, Pakistani, Bangladeshi, Black Caribbean and Black African groups achieve an average points score around three points lower than White British pupils (Minority Ethnic Pupils In The Longitudinal Study Of Young People In England, University of Warwick, July 2007).

- All the minority ethnic groups within the Black category and pupils of Mixed White and Black Caribbean heritage are consistently below the national average across Key Stages 1, 2 and 4 (DCSF: Attainment by Pupil Characteristics, in England 2007/08).

- Pupils from minority ethnic groups and pupils of mixed White and Black Caribbean heritage are consistently below the national average across all key stages, at GCSE and equivalent (DfES Statistical First Release 09/2006).

- Bangladeshi and Pakistani pupils perform below the national average across all Key Stages (DCSF: Attainment by Pupil Characteristics, in England 2007/08).

- In 2006 at KS2 Level 4+, pupils of African, African-Caribbean, Bangladeshi and Pakistani backgrounds achieved below national averages in English and mathematics, with the gap being significantly wider in mathematics. The gap in mathematics was 12 percentage points in the case of pupils of African backgrounds, 13 for those of African-Caribbean background, five for those of Bangladeshi background, and 11 for those of Pakistani background and at GCSE $5+A^{*}-C$, the gap in attainment when English and mathematics was taken into account was 9.4 percentage points in the case of pupils of Pakistani background, 5.2 for those of Bangladeshi background, 14.6 for those of African-Caribbean background and 6.6 for those of African backgrounds. These two sets of figures cited mask substantial differences between boys and girls and, in the case of Pakistani-heritage communities, substantial regional differences. 
(Developing the Equalities Agenda, 2008 and Beyond: The duties of schools and local authorities, DCSF, 2008).

- Pupils of Mixed White and Asian heritage and Irish pupils achieved above the national average for Foundation Stage Profile and Chinese pupils, pupils of Mixed White and Asian heritage and Indian pupils achieved above the national average for Key Stage 1(DCSF: Attainment by Pupil Characteristics, in England 2007/08).

- Chinese, pupils of Mixed White and Asian heritage and Indian pupils consistently achieve above the national average across Key Stage 1, Key Stage 2 and Key Stage 4 (DCSF: Attainment by Pupil Characteristics, in England 2007/08).

- The performance of the major census groups, Black, Asian, and Mixed has improved faster than the cohort average at both primary and secondary levels over the last few years. However the absolute achievement for some minority ethnic groups still lags behind the cohort as a whole (Breaking the link between disadvantage and low attainment, DCSF, 2009).

Children from the Gypsy, Roma and Traveller communities

- Gypsy/Romany and Traveller of Irish Heritage pupils perform considerably below the national average across Key Stages 1,2 and 4. However, it should be noted that very small numbers of pupils were recorded in these two categories (DCSF: Attainment by Pupil Characteristics, in England 2007/08).

- Travellers of Irish heritage and Gypsy or Roma pupils are overrepresented among many categories of SEN (SEN and ethnicity: issues of over- and under-representation, Lindsay, Pather, Strand, University of Warwick 2006).

- It is likely that a large proportion of Gypsy, Roma and Traveller children do not identify themselves as such for fear of being singled out.

\section{Exclusions}

- The rate of permanent exclusion was highest for Gypsy/Roma (0.56 per cent of the school population), Traveller of Irish Heritage ( 0.53 per cent of the school population), and Black Caribbean ( 0.36 per cent) ethnic groups. Black Caribbean pupils are 3 times more likely to be permanently excluded than the school population as a whole (caution is recommended in interpreting the data for Traveller of Irish Heritage children and Gypsy/Roma children due to potential under-reporting for these ethnic classifications) (DCSF Statistical First Release18/2009).

- The rate of fixed period exclusion was highest for Gypsy/Roma (18.71 per cent of the school population), Travellers of Irish Heritage (16.65 per cent) and Black Caribbean (11.06 per cent) ethnic groups. Black Caribbean pupils are nearly twice as likely to receive a fixed period exclusion than the school population as a whole (DCSF Statistical First Release 18/2009).

- In 2005/6, 45.47 per cent of Irish Traveller boys and $46.59 \%$ of Roma boys were excluded for a fixed term (DCSF Statistical First Release 21/2007). 


\section{Gender}

\section{General}

- A Teen Abuse Survey by Sugar magazine and the NSPCC in 2005 found that one in five teenage girls has been hit by a boyfriend, and one third of teenage girls say that cheating justifies violence. Research indicates that children who have witnessed domestic violence are 2.5 times more likely to have serious social and behavioural problems than other children. It is important to educate children and young people that any kind of violence or coercion has no place in a mutually respectful relationship.

- With regard to health, children born to teenage mothers have 60 per cent higher rates of infant mortality and are at increased risk of low birth weight, which has implications for the child's long-term health; teenage mothers are also three times more likely to suffer post-natal depression than older mothers and experience poor mental health for up to three years after the birth; and teenage parents and their children are at increased risk of living in poverty (Teenage Pregnancy Next Steps, 2006).

\section{Education}

- Since 1988, on the threshold measure of 5+ A-C GCSEs, a significant gender gap in favour of girls has emerged (Developing the Equalities Agenda, 2008 and Beyond: The duties of schools and local authorities, DCSF, 2008).

- Girls outperformed boys in virtually all ethnic groups for both Foundation Stage Profile and Key Stage 1(DCSF: Attainment by Pupil Characteristics, in England 2007/08).

- When looking at $5+A^{*}-C$ grades including English and mathematics, the national difference between boys and girls is 8.2 percentage points (DCSF: Attainment by Pupil Characteristics, in England 2007/08).

- About 30 per cent of all young people aged 16 are 'low achievers', in the sense that they have few if any valuable qualifications. Within this group boys outnumber girls by three to two (Cassen and Kingdon, 2007).

- Post-16 participation rates vary by gender: girls are more likely to stay on in full time education at age $16-82$ per cent of girls compared with 72 per cent of boys (Gender Gaps in Higher Education Participation, Report by DIUS, 2008).

\section{Employment}

- In 2004 the ratio of the ratio of women's to men's average earnings was 82 percent, and there are 'continuing and entrenched gender differences in subject choice' which 'impact on career paths and subsequent wage potential, particularly affecting women' (Gender and Education: the evidence on pupils in England, DfES 2004).

- If the purpose of equality in gaining educational qualifications is to ensure equality of opportunity in the labour market, then the importance of the gender gap in education can be assessed in relation to labour market 
outcomes. In other words, it could be argued that the widening gender gap does not matter if this advantage either disappears by the time the girl enters the labour market or if it helps to ensure greater equality for women in the labour market (Gender and Education 2004).

\section{Exclusions}

- In 2007/08 the permanent exclusion rate for boys was approx 3.5 times higher than that for girls. Boys represented 78 per cent of the total number of permanent exclusions each year (DCSF Statistical First Release 18/2009).

- Boys are more likely to be excluded (both permanently and for a fixed period) at a younger age than girls, with very few girls being excluded during the primary years. The most common point for both boys and girls to be excluded is at ages 13 and 14 (equivalent to year groups 9 and 10); around 52 per cent of all permanent exclusions were of pupils from these age groups (DCSF Statistical First Release18/2009).

- In 2007/08 the fixed period exclusion rate for boys was almost 3 times higher than that for girls (DCSF Statistical First Release18/2009).

- Boys accounted for some 75 per cent of all fixed period exclusions (DCSF Statistical First Release18/2009).

\section{SEN}

- At Key Stage 1, Key Stage 2, GCSE and equivalent and at Post-16 there are more boys than girls in each category of SEN. Boys with statements outperform girls with statements at every Key Stage and at GCSE and equivalent. However, at Post-16 girls with statements outperform boys (Gender and Education 2004).

Other areas of potential inequality:

\section{Deprivation}

- A deprivation attainment gap (measured by entitlement to free school meals) was observed in English and maths at primary and at secondary school. In each subject, a gap opens at Key Stage 1 and increases by Key Stage 4. At Key Stage 4 there was a 29 percentage point gap between pupils eligible for free school meals and those pupils who were not, in English in 2007, and a 28 percentage point gap in maths (Deprivation and Education The evidence on pupils in England -Foundation Stage to Key Stage 4, March 2009).

- Pupils eligible for FSM are less likely to achieve the Key Stage 4 threshold measure of $5+A^{*}-C$ GCSEs including English and maths. Only $21 \%$ of FSM pupils achieved 5+ $A^{*}-C$ GCSEs including English and maths in 2007 compared to $49 \%$ of non FSM pupils. A non FSM pupil has over three times the odds of achieving these thresholds compared to an FSM pupil (Deprivation and Education The evidence on pupils in England Foundation Stage to Key Stage 4, March 2009).

- Children who are eligible for free school meals are around 3 times more likely to receive either a permanent or fixed period exclusion than children 
who are not eligible for free school meals (DCSF Statistical First

Release18/2009).

\section{Age}

- The IFS report 2007 "When you are Born Matters" identifies that children born at the end of the academic year do less well in statutory end of Key Stage assessment than older children.

\section{Sexual Orientation}

- At schools where children are taught about gay issues and explicitly taught that homophobic bullying is wrong, lesbian and gay pupils are 13 per cent less likely to experience homophobic bullying (Report by Stonewall 'The experiences of young gay people in Britain's schools'). 


\section{A Guarantee for Pupils and Parents}

The Pupil and Parent Guarantees were first set out in the White Paper Your child, your schools, our future: building a 21st century schools system. The White Paper states:

'We want to maximise the chances of every child succeeding at school and being equipped to make a full contribution to society and the economy in later life. So we will build on the common core entitlement to learning which the National Curriculum sets out for pupils at maintained schools by now guaranteeing a set of key entitlements for pupils and their parents'

The aim of the guarantees therefore is to ensure pupils, parents, schools and local authorities are clear about what pupils can expect from their time at school, and what parents can expect for their children. By publishing the entitlements of a pupil or parent in a document, everyone will have a concise understanding of the purpose of the $21^{\text {st }}$ century schools system; will understand who is supposed to deliver its elements; and what pupils and parents can do if they are not receiving it. In turn, this is intended to drive improvement of the system by giving pupils and parents the ability to insist on the good provision they are intended to have and to enable teachers and those in the education system to understand their roles and responsibilities, and have a clear vision to inform their priorities.

If parents felt that the guarantees were not being met, under the new Parental Complaints Service they will be able to use the school's complaints procedure then, if not satisfied, go to the Local Government Ombudsman (LGO).

The Parent Guarantee will ensure that schools work with mothers, fathers and other carers as full partners in their child's learning and wider development.

The Pupil Guarantee gives every child and young person an entitlement to:

1. Every pupil will go to a school where there is good behaviour, strong discipline, order and safety;

2. Every pupil will go to a school where they are taught a broad, balanced and flexible curriculum including skills for learning and life;

3. Every pupil will go to a school where they are taught in a way that meets their needs, where their progress is regularly checked and where additional needs are spotted early and quickly addressed;

4. Every pupil will go to a school where they take part in sport and cultural activities; and

5. Every pupil will go to a school which promotes their health and wellbeing, where they have the chance to express their views, and where they and their family and welcome and valued.

The new Parent Guarantee will ensure parents have:

1. opportunities, information and support to exercise choice with and on behalf of their child

2. a Home School Agreement outlining their rights and responsibilities for their child's schooling 
3. the opportunity, information and support they need to be involved and engaged in their child's learning and development

4. access to a variety of activities, facilities and services, including support and advice with regard to parenting

The Bill will introduce a duty for the Secretary of State to consult on and then issue a document (or documents) setting out the Pupil and Parent Guarantees), but will not include the actual content of the Guarantees. Taking this legal route will mean that before the documents carry the rule of law they will be considered by parliament, and at that stage a full Equality Impact Assessment will be published on the relevant policies.

This Equality Impact Assessment is concerned with the principle of the introduction of the duty on the Secretary of State to publish such a document.

\section{Specific evidence for these provisions}

As well as considering the relevant evidence on how disability, ethnicity and gender effect children in the schools system, because parental engagement has a significant impact on attainment (Desforges, C. with Abouchaar, A.), it is necessary to consider how these issues affect parental engagement.

\section{Parents - disability}

- There is evidence that suggests that disabled parents do not have the same degree of confidence or experiences of services from schools as other parents - PICE, 2007 study:

$\circ$ overall, $12 \%$ of parents in the survey said that their child had been identified as having Special Educational Needs (SEN), and 6\% had a Statement of SEN. In these households, parents were more likely than average to have a long-term illness or disability and to be in a lower social grade. The survey findings show various sub-group differences, but some of the strongest impacts and most consistent differences have been found in respect of parents of children with Special Educational Needs (SEN).

- Parents of children with statements of SEN were more likely to feel very involved in their child's education (63\% versus $51 \%$ overall). Parents of children with SEN were also more likely to want to increase their involvement in their child's school life $(70 \%$ of parents of children with identified SEN and $73 \%$ of parents of children with a statement wanted to be more involved). (PICE: Peters, M., Seeds, K., Goldstein, A. and Coleman, N. (2008).

- In line with the more general survey findings, $84 \%$ who felt not very or not at all involved wanted to do more. However, even amongst those who already felt very or fairly involved, $70 \%$ still wanted to do more. The data therefore show a clear desire for parents of children with SEN to be involved in their children's schooling. (PICE: Peters, M., Seeds, K., Goldstein, A. and Coleman, N. (2008). 


\section{Parents - ethnicity}

Evidence shows that ethnicity has an impact on parents' views on education:

- Gutman and Akerman (2008) found that parents of Black children:

- place a high value on education

$\circ$ think that their children need to be actively encouraged to achieve their potential

- help out with homework more than average

o think that it is the parents' responsibility to ensure that their children do their best at school and enjoy their education

- want their child to go to university

- Black children are more likely than average to say that they are praised all the time; enjoy going to school; and value a degree. (DCSF 2007074, 2008).

- Research on the views of parents from different ethnic communities in England found that Black and Asian parents placed an extremely high importance on the value of education and expressed a great deal of concern about the future of their children. (Barn, R., Ladino, C. and Rogers, B. (2006) Parenting in multi-racial Britain. Parenting in Practice series National Children's Bureau). Good education was viewed as very important to combat racial discrimination and disadvantage and to prevent social exclusion. Feedback from stakeholders suggests however that Black parents are less likely to feel satisfied with their relationship with their child's school.

There is evidence that aspirations of parents and pupils are affected by their ethnic group but that this does not necessarily convert into academic success.

- Gutman and Akerman 2008 noted the higher aspirations of both parents and children amongst many minority ethnic groups, but these were not necessarily associated with higher achievement. Aspirations help mitigate the effects of low socio-economic background for certain minority groups, such as Indian and Chinese students; however, the effects are less strong for Pakistani and Bangladeshi students and least strong for Black Caribbean young people (Strand, 2007).

- Whilst high parental and pupil aspirations may lessen the effects of low socio-economic background, the effects vary amongst different ethnic groups. For example Black Caribbean young people have poor progress (even when a broad number of socioeconomic variables were included in the analysis) despite high educational aspirations of parents and pupils. This suggests the need to ensure that practical and attitudinal obstacles are also addressed alongside measures which support aspirations (Gutman and Akerman 2008).

The level of parental involvement has been shown to be affected by ethnicity.

- A survey of parents in 2007 (Peters, M., Seeds, K., Goldstein, A. and Coleman, N. (2008) Parental Involvement in Children's Education 2007. 
Research Report. DCSF RR034) found variation in levels of parental involvement among different ethnic groups. For example,

- Black parents are more than twice as likely as White parents to say they felt very involved in their child's education

- Parents from non-White ethnic backgrounds are also more involved in their child's school activities (including homework).

$\circ$. Parents from non-White backgrounds are also less likely to say that a child's education is the school's responsibility rather than the parent's (17\% of Black and Asian parents compared to $27 \%$ of White parents said that it was the school's responsibility)

\section{Parents - gender}

- There is evidence that some groups, in particular females, may be more likely than others to experience an 'aspiration-achievement gap'; which is the difference between their aspirations and educational achievement (Gutman and Akerman 2008).

- In two-parent households, it is common for both parents to share some involvement in their child's school life, although women tended to feel more involved than men (53\% compared with $45 \%$ felt very involved) (Gutman, L.M. and Akerman, R. (2008))

- Levels of fathers' involvement in their children's education Studies suggest that fathers' involvement has increased since the 1970s, particularly with children under the age of 5 (O'Brien, M. and Shemilt, I (2003). Working fathers: Earning and caring. Manchester: Equal Opportunities Commission).

- There is evidence, however, of great variation in levels of fathers' involvement, so that even though levels have increased on average, a substantial proportion of fathers recorded no daily direct interaction time with their children (Fisher,K., McCulloch, A., and Gershuny, J. (1999) British Fathers and Children working paper. Essex. Institute for Social and Economic Research cited in O'Brien and Shemilt (2003) Working fathers: Earning and caring. Manchester: Equal Opportunities Commission). This is likely to reflect, in part, changing family structures.

- When surveyed in 2007 (The Impact of Parental Involvement on Children's Education, 2007) mothers are more likely than fathers to say that they felt 'very involved' in their child's education (53\% compared to $45 \%$ ). Nearly $70 \%$ of fathers want to be more involved in their child's education and even higher proportions of non resident parents $(81 \%)$, who are predominantly male, are also keen for greater involvement. Fathers help less often with homework than mothers, however amongst parents working full time there was no gender difference.

- Research suggests fathers are involved (more often than mothers) in specific types of activities in their children's out of school learning: such as building and repairing, hobbies, IT, maths and physical play. And that the quality and content of fathers' involvement matter more for children's 
outcomes than the quantity of time fathers spend with their children (Goldman, R (2005). Fathers' Involvement in their Children's Education. London: National Family and Parenting Institute).

- Research indicates that fathers' involvement is important not only when a child is in primary school but also when they are in secondary school and regardless of the child's gender (i.e. for sons as well as daughters) (Goldman, R (2005). Fathers' Involvement in their Children's Education. London: National Family and Parenting Institute).

\section{Opportunities and Challenges}

\section{Opportunities}

There is potential for the Guarantees to significantly reduce existing inequalities, because the universal guarantees will ensure pupils and parents can have more equal access to and experiences of services.

The guarantees will set out the roles and responsibilities of schools and all parents, including those parents, highlighted previously in this document, who may be disadvantaged because of issues surrounding ethnicity, disability or gender.

One of the overarching ambitions of the Guarantee is that children have a personalised experience, and where that is the case, it is more likely that barriers to the achievement of any child will be addressed and removed.

For example, boys are currently achieving lower attainment than girls at school, and this situation may be improved through delivery of the Pupil Guarantee. The focus on catch up support, 1:1 entitlement and personal tutors may provide the necessary personalisation of education to ensure that boys are engaged with their learning, and improve their attainment.

There is an opportunity to change the nature of the expectation that pupils and parents have of schools and local authorities. While these expectations will still be flexible, the guarantees have the potential to introduce a consistent and universal baseline about the teaching and support available to help children's learning. As part of a package of new parental engagement commitments, including the Home School Agreements, the aim is to help all parents work more effectively with schools to help their children which will improve attainment levels.

\section{Challenges}

This presents some challenges and risks. There is some evidence to suggest that there is limited knowledge in schools of the complexities surrounding race, gender and disability. In particular, schools need a stronger understanding of differences between the needs of different minority ethnic groups, as well as the range of factors that affect each individual pupil's needs, including but not limited to their ethnicity. 
There is a risk that in implementing this policy, groups who have been traditionally less engaged with the education system will be less aware of the Guarantees, thus not promoting the equalities envisaged. In order for this policy to be successful, it will need to be vital to ensure everyone understands the consistent set of entitlements.

\section{Equality impact assessment - a positive impact is explicitly intended and very likely.}

\section{Analysis:}

The overall intention of both the Pupil and Parent Guarantees are to spread the practice of the best schools to all schools, and all children, so that everyone, regardless of background, disability, ethnicity or gender has equal access to a good quality education and support, and therefore enhanced life chances. The concept of the Parent and Pupil Guarantees is to set out very clearly those things that every pupil is entitled to.

Offers which have previously reached the significant majority of the pupil population, but have failed to benefit the most difficult-to-reach pupils will become guarantees, which must be delivered to these children. This is particularly true given that the guarantees are to be supported by a strong system of redress, operating through the Local Government Ombudsman.

For example, the Pupil Guarantee will enable children with disabilities, who are currently less likely to be accessing those services described in the guarantee, to seek redress if they are not benefiting from the guarantees. This means they can ensure that they receive equal benefit from the government's pledges.

While schools will have a duty to promote improved educational outcomes and well-being for all children, the personalised approach inherent within the Guarantees should ensure that the particular needs of disadvantaged groups are addressed.

Some groups of parents (including some ethnic groups, parents with disabilities, fathers, hard to reach parents etc.) can be held back by poor relationships with schools. The Guarantees will help less confident parents to engage in a more effective and regular dialogue with their child's school. They will also provide a firm foundation to help less confident parents by ensuring that they have a consistent expectation of how they can work more closely with the school to improve their child's attainment, progress, behaviour and other outcomes.

Elements of the Parent Guarantee will also ensure that parents can get support to help them engage with their children's learning and development, strengthening that positive impact on children's outcomes. This may include support for parents to address issues, for example low confidence in formal 
education or poor literacy skills, that parents developed as a result of poor experiences they had at school themselves.

The Guarantees will give pupils and parents the confidence and basis to approach their school if they do not feel that an element is being delivered. They will therefore be more likely to approach the school asking for the element to be delivered, and the school is more likely to provide it. This way, increasing awareness about what every child should experience at school will lead to demand-led improvements as well as 'top down' improvements as a direct result of the legislation.

\section{Improved communications between school and home}

There is clear evidence that some groups are disadvantaged by poor educational outcomes. The focus towards each pupil and commitment for improved communications should help parents from these groups to improve their relationships with their children's school, and their understanding of their child's learning goals and progress. This in turn should help to remove barriers to achievement and attainment; and may have a positive effect on reducing existing attainment gaps by ethnicity, gender and disability.

\section{Behaviour and exclusions}

It is also anticipated that the Guarantees will have a beneficial effect on behaviour, and that this may help to reduce exclusions from school. At present, some groups of pupils (particularly those with disabilities or SEN, boys, and children from some ethnic groups), are more likely to be permanently excluded from schools. The Guarantees, particularly the Parent Guarantee, will set out behavioural expectations for all children and will be closely linked with existing behaviour enforcement mechanisms (like Parenting Contracts and Orders).

Guidance will set out clearly how the component entitlements will be met, who is responsible for delivering each entitlement and how pupils and parents can seek redress if they are not delivered.

\section{Next steps}

The detail of the content of the Guarantee documents themselves will be subject to consultation and an Impact Assessment before being considered by parliament. At that stage a full Equality Impact Assessment will be published on the relevant policies.

When the final Guarantee document is published, it is likely to include guidance to support schools to deliver each element, including illustrative examples. This will provide an opportunity to include examples which support equality, thus reinforcing the message about the importance of addressing inequality in the school system.

The full document will be in plain English, which will advantage those who would normally find it difficult to understand legislation, and will therefore promote the opportunities of those people. There will also be consideration 
about whether the document should be made available in community languages. 


\section{Home School Agreements (HSAs)}

Other than the statutory requirement for schools to provide annual reports on pupils' performance to their parents, and to have prospectuses and HSAs (and the Early Years Framework for Schools (EYFS) which includes a duty for schools to work closely with the parents of early years children); there is little legislative underpinning to the partnership with parents around their child's learning and development at present, unless that child has special educational needs (SEN), or is in care.

In the Children's Plan: One Year On Progress report (December 2008), Ministers committed to a programme of action within the existing legislative framework to reinforce parental engagement (in addition to existing legislative requirements, this also takes in the continuing roll out of Parent Support Advisors; the Ministerial expectation that all schools will be able to report to parents on their children's progress; and a review of the information and guidance available to parents). But the legislative underpinning has not kept pace with the policy intention, and Ministers signaled in the consultation document 21st Century Schools: A World-Class Education for Every Child their intention to look at options for going further to embed parental engagement, and committed to strengthening current legislation on the statutory information provided by schools to parents so that there is a legislative basis for partnership working between schools and parents. The White Paper Your child, your schools, our future: building a $21^{\text {st }}$ century schools system (June 2009) includes a number of new commitments aimed at improving parental engagement, including strengthening existing HSA legislation.

It is intended to strengthen existing parental engagement legislation so that there is a more wide-ranging legal requirement for schools to work in partnership with parents. The proposed revisions to HSAs form part of a package of new and revised parental engagement legislation alongside a new Parental Guarantee; and revisions to existing secondary legislation on annual pupil reports and school prospectuses. The new HSA legislation is intended to clarify the roles and responsibilities of parents, schools and pupils in each child's learning through:

- improved articulation of each child's own personal learning and development needs; linking HSAs to existing enforcement mechanisms like parenting contracts and orders

- ensuring that wherever possible, all adults with parental responsibility are involved in the HSA process.

If parents felt that the school's stance on the HSA was not reasonable or that the school was not complying with the HSA they would, under the new complaints arrangements, be able to use the school's complaints procedure then, if not satisfied go to the Local Government Ombudsman (LGO). 


\title{
Specific evidence for these provisions
}

\author{
Home School Agreements
}

A 2003 evaluation of HSAs (Evaluation of Home School Agreements; Sheffield Hallam University; 2003. DFES Research Report RR455, 2003) indicates that at the time of the research, $99 \%$ of the schools surveyed had an HSA in place; in over three quarters of these schools, at least $75 \%$ of parents had signed their school's HSA.

The research found that when implemented with full and open discussion, HSAs can enhance trust and understanding between parents and schools. On the other hand, the research also indicates that parents can find HSAs patronising and, because they are not legally enforceable, of limited value.

The 2007 Parental Involvement in Children's Education (PICE) research found that awareness of HSAs has not changed since 2001.

\section{Parental engagement}

As set out in the section above on the Pupil and Parent Guarantee, there is evidence that parental interest in and engagement with their child's individual educational progress has a positive influence on outcomes. In the early years there is common agreement about the activities in the home which contribute to a high quality learning environment but there is no such commonly agreed set of home characteristics exist for older children.

While most parents want their children to do well, the most socio-economically deprived parents can lack the skills and confidence to work with schools; and schools can often find parents from deprived backgrounds difficult to work with. DCSF research (Deprivation and Education: the evidence on pupils in England, Foundation Stage to Key Stage 4; March 2009, p63) demonstrates that the extent and form parental involvement takes is strongly influenced by socio-economic background and material deprivation

\section{What the evidence shows - key facts}

\section{General}

The evidence set out in the Chapter on the Pupil and Parent Guarantee, relating to parental engagement, is equally relevant to this policy.

Schools which might be characterised as strong on personalised learning see learners as co-investors in education, not in the financial sense, but in terms of their aspirations and commitment to learning. They maintain the focus on learning and all other activities are seen as contributing to this. However, the learning on which they focus goes beyond the school to future employment, health and citizenship. It is exemplary in lifelong learning, by giving pupils the 
skills to learn and motivating them to succeed in their own interests and aspirations and hence in their own terms (DCSF RR843, 2007).

Most parents have high aspirations for their young children; however these aspirations are likely to change as children grow older because of economic constraints, children's abilities and the availability of opportunities. (Gutman and Ackerman 2008)

Although aspirations significantly predict attainment, regardless of socioeconomic background, they may be stronger predictors of achievement for young people from more advantaged (socio-economic) backgrounds. (Gutman and Ackerman 2008)

There is evidence that some groups (in particular females, those from lower socioeconomic backgrounds and some ethnic minorities) may be more likely than others to experience an 'aspiration-achievement gap'; which is the difference between their aspirations and educational achievement. (Gutman and Ackerman 2008).

Women, parents with young children, parents who left full-time education later (i.e. those who left at age 21 or over) those from Black or Black British backgrounds and parents of a child with a statement of Special Educational Needs are all more likely to feel very involved (compared with men; parents who left education at a younger age; and parents from White or Asian backgrounds respectively). Lone parents and non-resident parents are both less likely than average to feel very involved. (Peters, M., Seeds, K., Goldstein, A. and Coleman, N. (2008).

\section{Disability}

As set out in the evidence section, exclusions data from DCSF SFR18/2009 demonstrates that pupils with SEN are significantly more likely to be excluded from school than their peers.

For children with SEN, the Lamb Inquiry highlighted the importance of good relationships between parents of children with SEN and their children's schools. The new HSAs will therefore be informed by the Lamb Inquiry's principle of rationalising SEN information to parents and securing greater parental involvement. Most of the 1.5 million children with SEN already have personalised learning plans. Personalisation is fundamental to meeting the needs of children with special educational needs and any support and interventions can be captured as part of the HSA.

\section{Ethnicity}

Parents of Black children: place a high value on education; think that their children need to be actively encouraged to achieve their potential; help out with homework more than average; think that it is the parents' responsibility to 
ensure that their children do their best at school and enjoy their education; and want their child to go to university (DCSF 2007074, 2008).

\section{Challenges and opportunities}

The new HSAs will set out the roles and responsibilities of schools and parents, so that parents are better equipped to help with their child's learning; and to address any behavioural concerns at an early stage. This should help all parents to work more effectively with schools, but the new HSAs be particularly helpful to those parents who may be reluctant to work with schools (due to, for example, low confidence levels, or having experienced negative outcomes at school themselves).

The aim is that schools and parents will have flexible but consistent expectations of how they can help children's learning. As part of a package of parental engagement commitments, including the new Parental Guarantee, HSAs will help all parents work more effectively with schools - the legislative proposals for HSAs will include behavioural goals which will be linked to behavioural support mechanisms to make the responsibilities of schools and parents around children's behaviour more clearly understood and enforceable. This should mean that behavioural issues can be addressed at an earlier stage (which should result in less time being spent by schools in dealing with behavioural problems, and ultimately fewer exclusions - and, as the evidence above demonstrates, some groups of children are currently more likely to be excluded than others).

The proposed revisions to the HSA legislation aim to help all parents to engage more effectively in their children's learning (with the overall outcomes being improved attainment and better behaviour in the classroom). But there some groups of parents who are more effective in engaging with their children's learning than others. It is hoped that the new HSAs will, as part of a package of parental engagement initiatives, be particularly helpful to those types of parents who may at present find it difficult to work with schools.

There are some challenges and risks attached to the policy. It is important that HSAs help all parents, and their implementation must not further disadvantage any specific groups of parents. We need to consider, for example, that the more personalised approach could potentially exacerbate differences because if policies fail to engage in a meaningful way with these groups, they will remain marginalised and improvements will disproportionately benefit pupils and parents who are already well engaged with the school system.

As mentioned previously, there is some evidence to suggest that schools need to develop a better understanding of differences between the needs of different minority ethnic groups, and the factors that affect each individual pupil's needs. This would, of course, affect all policies where there are diversity-related concerns, including the revised HSA legislation. 
It is hoped that the proposed revisions to the HSA legislation will help to address these concerns. Research on HSAs has shown that when implemented with full and open discussion, HSAs can enhance trust and understanding between parents and schools. When used effectively, HSAs are a powerful vehicle for articulating each child's own personal learning and development needs, and the new HSAs legislation will place a duty on schools to work more closely with families to provide a personalised and regularly updated HSA for every child, including individualised goals and targets around curricular educational objectives, and wider aims like health and wellbeing, or participating in extended schools provision.

\section{Equality impact assessment}

A positive impact is explicitly intended and very likely.

The overall intention of the new Parent Guarantee is to spread the practice of the best schools to all schools, and all children, so that everyone, regardless of background, disability, ethnicity or gender has equal access to a good quality education, and therefore enhanced life chances.

The new HSAs will be a key component in the Parent Guarantee, and as such there is potential for HSAs to reduce existing inequalities. While schools will have a duty to promote improved educational outcomes and well-being for all children, the personalised approach of the new HSAs should ensure that the particular needs of disadvantaged groups are addressed.

Some types of parents (including some ethnic groups, parents with disabilities, fathers, hard to reach parents etc.) can be held back by poor relationships with schools. The new annual review process for HSAs will help less confident parents to engage in a more effective and regular dialogue with their child's school. The personalisation of HSAs will also help less confident parents by ensuring that they have a consistent expectation of how they can work more closely with the school to improve their child's attainment, progress, behaviour and other outcomes. Revisions to school complaints procedures will improve means of redress for parents who do not feel that the school is meeting its obligations, as set out in the HSA.

The Government's proposals will not make signing the Home School Agreement a requirement or condition of admission to a school because that could unfairly disadvantage some children and their parents from seeking or accepting a place. The Admissions Code underpins the Government's aim to create a schools system where all parents feel they have the same opportunities to apply for and secure a place at the schools they want for their child. The Code is clear that signing the Home School Agreement should not be a condition of an offer of a place at a school. The Government does not want it to be possible for Home School Agreements to be exploited as a means of sifting applicants and excluding some children which would be likely to have a disproportionate impact on already disadvantaged children. 


\section{Behaviour and exclusions}

It is anticipated that the new HSAs will have a beneficial effect on behaviour, and that this may help to reduce exclusions from school. At present, some groups of pupils (particularly those with disabilities or SEN, boys, and children from some ethnic groups), are more likely to be permanently excluded from schools. The new HSAs will set out behavioural expectations for all children and will be closely linked with existing behaviour enforcement mechanisms (such as Parenting Contracts and Orders)

The new annual review process for HSAs and a better, more informed and regular dialogue between schools and families should ensure that all parties have a better understanding of their behavioural responsibilities. This should in turn provide scope for earlier intervention, so that behavioural issues can be resolved before they escalate. In some cases, the actions needed to address behavioural issues and which are set out in HSAs will be formalised in Parenting Contracts and Orders; and it is likely that there will be an increase in behavioural Parenting Contracts and Orders. However, it is hoped that this will be offset by a reduction in the numbers of children being excluded from school, and that this will be beneficial to those groups currently more likely to be excluded.

\section{Personalised learning}

The new personalised HSAs will help to ensure that schools set out and regularly review with parents the individual needs of every child, and the personalisation of HSAs should have a beneficial impact on the outcomes of disadvantaged children. For example, the move towards personalisation of HSAs will ensure compliance with the Lamb Inquiry's recommendations on mainstreaming SEN and disability in schools, specifically:

- communication and engagement with parents rather than standard information;

- a reduction in the specific SEN requirements in favour of covering SEN and disability in information for all children and an increased focus on outcomes for disabled pupils and pupils with SEN. The HSA Guidance will make it clear that Head Teachers must ensure that the HSA process takes account of their duties under the DDA not to discriminate against the children for a reason related to their disability. The guidance will also ensure that the HSA guidance reflects the needs of children with SEN. Guidance will also address specific concerns relating to behaviour issues that some children with SEN may have (e.g. children on the autistic spectrum) and will not disadvantage disabled children, children with SEN or their parents.;

- an increased focus on outcomes for disabled pupils and pupils with SEN;

There is also clear evidence that some groups are disadvantaged by poor educational outcomes. The personalisation of HSAs, and the more regular 
reviews, should help parents from these groups to improve their relationships with their children's school, and their understanding of their child's learning goals and progress. This in turn should help to remove barriers to achievement and attainment; and may have a positive effect on reducing existing attainment gaps by ethnicity, gender and disability.

\section{Gender}

Where a child has different parents, the HSA Statutory Guidance will make it clear that head teachers have discretionary powers to issue different HSAs to different parents. In most cases, including where the parents do not live together, there will be one home-school agreement which will be signed by both parents. Guidance to head teachers will make clear that this power is available to them to help the small number of parents who do not live together and who do not have an effective working relationship.

Where schools have knowledge of a child's home circumstances, and contact details for both parents, and when the school considers it appropriate, it should be possible to construct a HSA for each parent that reflects accurately the level of involvement of that parent. The non-resident parent will be expected to sign the agreement whether it is a single agreement for both parents or a different one.

This we believe, should help them to become more active participants in their children's education - in particular fathers who are disproportionately not engaged. Research demonstrates that children do better if both their parents are involved with their learning, but for many reasons, non-resident parents can find it difficult to engage with their children's schools. Further research shows nearly half $(45 \%)$ of non-resident parents would like to be more involved in their children's education than they are at present.

\section{Next steps}

Subject to the will of Parliament, the revised HSA legislation would be accompanied by statutory guidance for head teachers, and non-statutory guidance for schools and local authorities. We will ensure that this guidance helps to raise awareness of groups of parents who may find it difficult to build strong links with schools; and that it includes information on working with disadvantaged groups so that the benefits will be shared equally.

We will also ensure that the specific needs of disadvantaged parents are taken into account in our wider parental engagement work. For example, we are undertaking research to highlight the types of parental engagement which have proved most effective, which will help schools and other settings to target communications in a more informed manner. This will be followed by the publication of guidance and materials designed to further assist schools, local authorities and other stakeholders in their engagement with parents. All of this work will be informed by examples of parental engagement that we are currently requesting from stakeholders. 
As part of our strategy, we are also considering how we can distribute messages for different groups of parents about the reasons for, and ways of engaging in their children's learning and development to use nationally and locally. In particular this will include materials aimed at narrowing gaps, and at specific disadvantaged groups. 


\section{Parental responsiveness}

\section{Objective}

The $21^{\text {st }}$ Century Schools White Paper sets out a coherent set of proposals to ensure the school system is responsive to the needs and preferences of pupils and their parents. One of the objectives of the 'parental responsiveness' policy is to ensure that Local Authorities (LAs) actively seek the views of all parents on a regular basis regarding the overall pattern of provision, thereby sharpening LA accountability to parents.

It is anticipated that, as LAs respond to parental concerns about provision, by, for example, improving teaching and learning at a particular school, or increasing places at a high performing school, standards will rise. As local school provision develops to better suit local needs and aspirations and children attend schools that better meet their needs, it is likely that children will do better and attainment will improve.

\section{Issue}

The current system is a reactive one, whereby LAs respond to parental dissatisfaction, usually in the form of individual appeals regarding the school place offered to a pupil, or by vocal and visible campaigns regarding local provision. These are more likely to made by parents who are adept at understanding and maximising their opportunities within the system.

Current policy largely focuses on school level issues and individual appeals or complaints. There is evidence to suggest that many parents feel unhappy with the overall offer in their area and, at present, robust mechanisms to address parental satisfaction are not in place. By surveying parents on an annual basis, LAs will be able to canvass the views of all parents, not just a voiciferous minority of parents who are better able to use the current system of individual representations and lobby groups.

\section{The policy}

The parental responsiveness duty will require LAs in England to ask parents of children in Year 6 their views on secondary school provision in their area, alongside the annual admissions process, each year. This will be via a survey that will ask how satisfied they are with local provision and the reasons why they are satisfied or dissatisfied.

We intend to consult on 'material parental dissatisfaction' being defined for the purposes of Clause 6 as:

(a) where there is a minimum response rate to the survey of at least $51 \%$ AND

(b) at least $51 \%$ of those responses are dissatisfied with the provision. 
Where the outcome of a survey shows material parental dissatisfaction with school provision locally, the LA would be required to address concerns in a published response plan. They will develop their plan in consultation with parents of children in Key Stage 2 (i.e. Years 3, 4, 5 and 6).

Parents will have an opportunity to comment on whether or not their views have been considered fully and the extent to which proposals address the parental concerns. If comments are 'not sufficiently favourable' - indicatively $20 \%$ or more of parents are unhappy with the plan (threshold subject to consultation) - then the LA must refer the plan to the Schools Adjudicator for a determination. The Schools Adjudicator will review the process and outcome and say whether the plan is reasonable. He can approve or reject the plan or direct the LA to make changes to it. Should parents still think the revised plan does not address their concerns, they will be able to complain to the Secretary of State.

\section{Specific evidence for these provisions}

There is some evidence to suggest that many parents feel unhappy with the overall secondary school offer in their area. National surveys indicate that the majority of parents are positive about the availability of a choice of good schools in their area, and with the school that their child attends (Ofsted surveys and the recent department parent surveys to support LA commissioning pathfinders are consistent on this). However, a significant minority remain dissatisfied $-71 \%$ of parents feel they have a good choice of state funded schools within their area (the remainder splits 50-50 between those who believe they have no choice, and those who believe they only have the choice of bad schools. Source - LA Commissioning Pathfinders National Survey). Almost one third of parents feel low confidence in overall quality in their area, and one fifth feel that the best case scenario (of getting their first choice) is less than ideal. There is also marked geographical variation, with just over half of parents in several London Boroughs getting their first choice secondary school (DCSF SSA01/2008). Furthermore, there is anecdotal evidence that some LAs are not responding proportionately to basic parental representations on the quality and pattern of provision and it should be noted that these are the cases that reach DCSF. It is difficult to know how many cases are resolved satisfactorily.

There is little evidence to suggest differences in participation in surveys between different BME groups, disabled parents or parents of disabled children, or gender. However, evidence from the commissioning pathfinders work ('Learning from experience: schools commissioning by local authorities' (2008), DCSF ) suggests that engaging hard to reach parents in decisions about local schools, remains a challenge.

\section{Challenges and opportunities}

This policy will ensure that LAs actively engage all parents in their planning of school provision. Some LAs already actively seek parents' views in shaping local services, but many do not. This policy would place a legal duty on LAs 
to survey all parents of children in year 6 on an annual basis. It will require LAs to analyse the data by area to enable them to look at patterns of parental views, thereby securing a detailed breakdown within the local area. Geographical area may also be a used as a proxy for socio-economic group which will enable LAs to monitor the efficacy of the policy in engaging the 'hard to reach' parent, one that perhaps historically, would not engage with the LA or their child's school, or respond to formal consultation exercises.

A key challenge however is to secure an adequate and balanced response rate. Surveys of this nature are prone to low response rates, in particular from more disadvantaged groups. Parents who have greater capacity to use the existing system are more likely to take part in the survey. Other parents who may not usually use existing mechanisms may not take part. However, recent focus group research with parents from a range of socio-economic groups ${ }^{1}$ found that all said they would be likely to complete this survey. Nevertheless, it will be crucial that LAs use innovative methods to increase the response rate from these groups and secure a representative response rate.

\section{Disability}

As all parents of children in year 6 will be asked for their views, parents of children with special educational needs (SEN) and/or disabilities will be included in the survey. These parents are likely to have unique views as well as needs and aspirations for their child's secondary schooling and therefore it is important that LAs look at this group carefully.

Some parents may be unable to respond to the survey because of their own special educational needs or disabilities and may need support in completing the survey. Choice Advisors (who work with disadvantaged or disempowered parents during the admissions process in the Autumn term of Year 6) will work with parents and support them in completing the survey. Parent support advisors may also be able to support parents in this way.

\section{Ethnicity}

As all parents of children in year 6 will be asked their views, parents of children from black and minority ethnic groups will be included in the survey. Some of these parents may have specific views or preferences for secondary schooling, for example, preferring their child attends a faith school.

\section{$\underline{\text { Gender }}$}

The survey may well enhance an LA's understanding of parents' preferences in respect of single sex schools.

\footnotetext{
${ }^{1}$ DCSF Customer Voice Research published 26 November 2009
} 


\section{Disadvantaged or 'Hard to reach' parents}

As outlined above, Choice Advisors will work with disadvantaged or hard to reach parents in explaining the purpose of the survey and supporting them to complete it. Parent support advisors, who work with disadvantaged parents, will also be able to encourage such parents to respond. It is important that these mechanisms are put in place to ensure that the parental responsiveness policy enables all parents to participate, not just those engaged or able parents. Small focus group work with parents from a range of socio-economic groups illustrated that those from more disadvantaged backgrounds were just as likely to respond to the survey as those living in more advantaged circumstances. By ensuring all parents have an equal opportunity to respond to the survey, LAs will have access to a full and balanced account of parents' views.

\section{Equality impact assessment}

An adverse impact is unlikely, and on the contrary the policy has the clear potential to have a positive impact by reducing and removing barriers and inequalities that currently exist.

The purpose of this policy is to encourage a representative view of all parents' needs and aspirations for secondary schools in their area. By actively seeking the views of all parents, it is likely that a more balanced view of school provision will be collected. The system will be enhanced from one that relies on reactive representations from parents who are already empowered to use existing mechanisms, to one that will actively encourage participation from all parents. Disadvantaged parents will be supported to participate in this exercise.

It is likely that, as LAs respond to parental concerns about provision, by, for example, improving teaching and learning at a particular school, or increasing places at a high performing school, standards will rise. As local school provision develops to better suit local needs and aspirations, and children attend schools that better meet their needs, it is likely that children will do better and attainment will improve.

\section{Next steps}

A trial with five local authorities took place from September to December 2009 to look at the various logistical and operational aspects of conducting the survey. It also looked at response rates to determine whether there is a bias towards any particular group, or whether key groups have not responded. A summary report of the trial has been published and will inform future implementation.

In order to promote equality:

- Large print and Braille versions of the questionnaire will be made available. 
- Choice Advisors (who work with disadvantaged or disempowered parents during the admissions process in the Autumn term of Year 6) will work with parents and support them in completing the survey. Parent support advisors will also be able to support parents in this way.

- The questionnaire will be available in community languages 


\section{Alternative Provision}

This clause will amend Section 19 of the Education Act 1996 to introduce a requirement for local authorities to arrange suitable, full-time education for all pupils in alternative provision, allowing an exception for children who for reasons which relate to their physical or mental health it would not be in the child's best interests for full-time education to be provided. If full-time education is not appropriate, the local authority will have a duty to arrange education on such part-time basis as the local authority considers to be in the child's best interests.

There is currently a limited duty on local authorities to arrange full-time education for children who have been excluded from school. The clause will extend the duty to cover all children including those with illness, disability, pregnancy, school phobia, and those awaiting a place in a maintained school. A specific duty to arrange full-time education was not previously extended to these pupils because they are children for whom full-time education might not always be appropriate. Although local authorities have had flexibility in dealing with these types of pupils, they have always been required to arrange "suitable education". "Suitable education" is defined in section 19 (6) as "efficient education suitable to his age, ability and aptitude and to any special educational needs he may have. We now want to ensure that all pupils who receive alternative provision receive suitable full-time education.

Section 19 of the Education Act 1996 and Section 100 of the Education and Inspections Act 2006 already provide that excluded children must be educated full time. (To note: there are prescribed exceptions in regulation which relate to SEN children where their statement says that they should be receiving less than full time education and a particular group in Year 11 who have already taken all public examinations they were entered for).

Up to now, there have been limited requirements placed on local authorities and schools regarding the alternative provision they make available to their pupils, except for those that have been excluded from school. It has largely been up to the commissioners of the provision, in conjunction with the provider, to decide the curriculum that pupils should receive and how many hours of provision they should be offered. This has resulted in a situation where pupils can wait for long periods for a placement and then, once they are placed, receive only a few hours of education in a week and have little opportunity to achieve accredited qualifications. Engagement in full-time education is proven to reduce the risk of offending and anti social behaviour in children and young people.

\section{Specific evidence for these provisions}

Sir Alan Steer's review of pupil behaviour: Final report (15 April 09) presents the overall conclusions of Sir Alan Steer's review of pupil behaviour issues, announced in the Children's Plan. It builds on findings from the four interim reports issued between March 2008 and February 2009, and recommends that minimum standards should be in place for alternative provision by Local 
Authorities. This new legal requirement provides a vehicle for putting such minimum standards on a formal and universal footing.

The evidence also includes statistical data on learners most likely to be in alternative provision, for example Short Stay Schools and children who have been excluded

Specific evidence relating to these provisions

DATA on Short Stay Schools (previously knows as Pupil Referral Units)

Jan 08 census data - pupil referral units

\begin{tabular}{|l|l|l|l|}
\hline & Total & $\begin{array}{l}\text { Solely } \\
\text { registered }\end{array}$ & $\begin{array}{l}\text { Dually } \\
\text { registered }\end{array}$ \\
\hline No. of pupils & 25,288 & 16,095 & 9,193 \\
\hline $\begin{array}{l}\text { SEN (with } \\
\text { statements) }\end{array}$ & $\begin{array}{l}3,261 \\
(12.9 \%)\end{array}$ & $\begin{array}{l}1,948 \\
(12.1 \%)\end{array}$ & $\begin{array}{l}1,312 \\
(14.3 \%)\end{array}$ \\
\hline $\begin{array}{l}\text { SEN (without } \\
\text { statements }\end{array}$ & $\begin{array}{l}15,685 \\
(62.0 \%)\end{array}$ & $\begin{array}{l}7,592 \\
(47.2 \%)\end{array}$ & $\begin{array}{l}8,093 \\
(88.0 \%)\end{array}$ \\
\hline $\begin{array}{l}\text { Gender } \\
\text { (Male) }\end{array}$ & $\begin{array}{l}17,531 \\
(69.3 \%)\end{array}$ & $\begin{array}{l}11,802 \\
(73.3 \%)\end{array}$ & $\begin{array}{l}5729 \\
(62.3 \%)\end{array}$ \\
\hline $\begin{array}{l}\text { Gender } \\
\text { (Female) }\end{array}$ & $\begin{array}{l}7,757 \\
(30.7 \%)\end{array}$ & $\begin{array}{l}4,293 \\
(26.7 \%)\end{array}$ & $\begin{array}{l}3,464 \\
(37.7 \%)\end{array}$ \\
\hline $\begin{array}{l}\text { Free school } \\
\text { meal (eligible) }\end{array}$ & $\begin{array}{l}6,785 \\
(26.8 \%)\end{array}$ & & \\
\hline $\begin{array}{l}\text { Free school } \\
\text { meal (known } \\
\text { to be taking) }\end{array}$ & $\begin{array}{l}4,165 \\
(16.5 \%)\end{array}$ & & \\
\hline
\end{tabular}

PUPIL REFERRAL UNITS: NUMBER AND PERCENTAGE OF PUPILS BY ETHNIC GROUP (1)

As at January 2008

England

Pupils of compulsory school

age and above

Number Percentage

$\begin{array}{lll}\text { White } & \mathbf{9 , 5 4 5} & \mathbf{7 7 . 1} \\ \text { White British } & 9,143 & 73.9 \\ \text { Irish } & 50 & 0.4 \\ \text { Traveller of Irish heritage } & 56 & 0.5 \\ \text { Gypsy/ Roma } & 70 & 0.6\end{array}$




\begin{tabular}{|c|c|c|c|}
\hline $\begin{array}{l}\text { Any other } \\
\text { background }\end{array}$ & White & 226 & 1.8 \\
\hline $\begin{array}{l}\text { Mixed } \\
\text { White and } \\
\text { Caribbean } \\
\text { White and Black Afric } \\
\text { White and Asian } \\
\text { Any other } \\
\text { background }\end{array}$ & $\begin{array}{l}\text { Black } \\
\text { ican } \\
\text { Mixed }\end{array}$ & $\begin{array}{l}382 \\
101 \\
54 \\
172\end{array}$ & $\begin{array}{l}3.1 \\
0.8 \\
0.4 \\
\\
1.4\end{array}$ \\
\hline $\begin{array}{l}\text { Asian } \\
\text { Indian } \\
\text { Pakistani } \\
\text { Bangladeshi } \\
\text { Any other } \\
\text { background }\end{array}$ & Asian & $\begin{array}{l}395 \\
45 \\
149 \\
116 \\
\\
85\end{array}$ & $\begin{array}{l}3.2 \\
0.4 \\
1.2 \\
0.9 \\
0.7\end{array}$ \\
\hline $\begin{array}{l}\text { Black } \\
\text { Black Caribbean } \\
\text { Black African } \\
\text { Any other } \\
\text { background }\end{array}$ & Black & $\begin{array}{l}926 \\
474 \\
324 \\
128\end{array}$ & $\begin{array}{l}7.5 \\
3.8 \\
2.6 \\
\\
1.0\end{array}$ \\
\hline Chinese & & 10 & 0.1 \\
\hline Any other ethnic grou & & 130 & 1.1 \\
\hline Classified (1) & & 12,377 & 100.0 \\
\hline Unclassified (2) & & 662 & 5.3 \\
\hline All pupils (3) & & 12,377 & 100.0 \\
\hline
\end{tabular}

- At any one time just under $1 \%$ of pupils $(70,000)$ are in some form of alternative provision but because many placements are short term the numbers passing through alternative provision in any one year are about double this - 135,000;

- $75 \%$ of pupils in alternative provision have special educational needs (62\% without statements and $13 \%$ with statements);

- the outcomes for pupils in alternative provision are generally very poor - in 2006 only $1 \%$ of 15 year olds in Pupil Referral Units achieved 5 GCSEs at grades $A^{*}-C$ or equivalent; $11.3 \%$ achieved 5 or more 
grades $A^{*}-G$; and $82.1 \%$ achieved 1 or more qualifications. This compares with $45.8 \%$; $90.5 \%$ and $97.8 \%$ in mainstream schools;

- There is no legislative requirement for the number of hours per week that pupils should receive in alternative provision, apart from for pupils who have been excluded from school - the legal requirement is that these pupils must have full-time education from the sixth school day of the exclusion. Local authorities are already funded to make full-time provision for permanently excluded pupils and there are just under 10,000 pupils who are permanently excluded each year. Guidance does recommend some minimum hours for other types of pupil - for example, 5 hours per week for pupils with medical needs - but this guidance is not in-depth and does not cover all kinds of pupil. We know that some local authorities nevertheless arrange full-time provision for most or all of their pupils but there is also anecdotal evidence that some pupils receive much less than this - sometimes as little as an hour a week (although this should not be the case for excluded pupils, where there is a legal entitlement) ;

- There is also no legal requirement for the curriculum that pupils should receive in alternative provision, apart from that it should be balanced and broadly based. Once again, while we know there is much good practice we are also aware that some pupils receive inadequate or unsuitable education in alternative provision and that pupils in Key Stage 4 do not always have the opportunity to study for and take accredited examinations.

- Reasons for accessing AP (2005 Survey findings):

- Medical needs, pregnancy and school phobic - $28 \%$

- At risk of exclusion $-27 \%$

- Permanent and fixed period exclusions - $21 \%$

- Other $-24 \%$

Characteristics of Excluded Pupils - see exclusions data in the general evidence chapter.

\section{Challenges and opportunities}

There is a range of reasons for pupils being in alternative provision. The biggest single group (just under 50 per cent) are pupils who either have been excluded from school or who have been deemed at risk of exclusion. Both categories include high numbers of children and young people with special educational needs. The other 50 per cent are in alternative provision either for medical needs (e.g. pupils with emotional and physical health needs and teenage mothers - a gender issue) or for other reasons (pupils unable to cope in mainstream school, children temporarily without a school place). $69 \%$ of the 
pupils are boys which is again a gender issue and, as seen from the statistical evidence, learners from certain communities are also over represented in the exclusion tables. The diversity of pupils for whom alternative provision must cater presents a real challenge in ensuring that they are all appropriately provided for. It is hoped that this legislation will improve their opportunities by ensuring that, where it is appropriate, a full time education is arranged for them.

\section{Equality impact assessment}

A positive impact is explicitly intended and very likely. This legislation is intended to ensure that young people get an entitlement to suitable and fulltime education, equal to that for young people in mainstream education.

\section{Next steps}

This legislation will be underpinned by guidance, which was be published for a a full public consultation which ends in March 2010. We shall also ensure that the guidance we are issuing on core education and curriculum for alternative provision places due emphasis on promoting equality.

We are piloting the collection of attainment data from Short Stay Schools in 2009 , and subject to the quality of this data being high enough, we intend to publish this in early 2010 for participant local authorities. We are putting in place a new Short Stay School / Alternative Provision Census regime from 2010, which should give robust data on attainment Short Stay School I Alternative Provision (for pupils at the end of key stage 4) across local authorities, available and published alongside the school attainment tables from January 2011.

The Department will be continuing to monitor and challenge disproportional exclusion rates and has strengthened guidance to behaviour and attendance partnerships to reflect this and encourage more strategic early intervention policies.

We will also seek to evaluate the impact of this legislation in late 2013, after the duty has been in place for 2 years. 


\section{SEN - Right to Appeal}

These provisions would introduce an additional right of appeal to the First-tier Tribunal (Special Educational Needs and Disability) in circumstances where, following a review of a child's statement of special educational needs, a local authority decides not to amend the statement.

\section{Description of the policy}

Children have special educational needs (SEN) where they have a significantly greater difficulty in learning than their peers or a disability which prevents or hinders the child from accessing the mainstream schools in the area. Just over twenty percent of the school population has SEN at any one time. At January $20091,433,940$ pupils had SEN without statements $(17.8 \%$ of the school population) and $221,670(2.7 \%)$ had statements.

The Education Act 1996 and associated statutory guidance in the SEN Code of Practice set out a framework for meeting children's SEN. The Code recommends a graduated approach to meeting children's SEN through School Action (children's SEN are met from within the school's normal resources), School Action Plus (the school receives some outside help to meet children's SEN) and SEN statements. Statements are legal documents drawn up by local authorities, following statutory assessments of children's SEN which set out what the child's SEN are, the special educational provision to meet those needs and the school or 'education otherwise than at school' where the child will have his or her needs met. SEN statements must be reviewed annually and there can also be additional interim reviews.

The SEN framework gives parents the right to appeal to an independent tribunal (the First-tier Tribunal (SEN and Disability), which is part of the Tribunals Service, an executive agency of the Ministry of Justice, in relation to various matters concerning the statutory assessments of their children's SEN and their children's statements. Parents can appeal to the Tribunal if a local authority amends a statement following a review but they do not currently have the right to appeal to the Tribunal if the local authority does not amend the statement following a review. This proposal seeks to rectify that.

There has been concern about parental confidence in the special educational needs and disability (SEND) 'system'. The Secretary of state asked Brian Lamb, Chair of the Special Educational Needs Consortium, to lead a group of experts in an Inquiry into the most effective means of increasing parental confidence and his final report was published on 16 December 2009.

This policy links into our over-arching aim to improve outcomes for children with SEN and disabilities by narrowing the gap in attainment between children with SEND and their peers (DSO4). The Lamb Inquiry, referenced in both the Children's Plan One Year On document and the Your child, your schools, our future: building a $21^{\text {st }}$ century schools system White Paper, has specifically recommended that parents should have a right of appeal where the local authority decides not to amend an SEN statement following an annual or interim review. 


\section{What the evidence shows - key facts}

In 2007-2008 3,392 appeals were registered with the First-tier Tribunal (SEND). Of the 3175 cases which were dealt with during that year $872(27 \%)$ were decided, $1214(38 \%)$ were withdrawn before coming to an appeal hearing and $1089(34 \%)$ were conceded by the local authorities before the hearing.

Within those figures 54 registered appeals were about a refusal to reassess, perhaps the closest type of appeal formally to the one which is being proposed, of which $10(19 \%)$ were decided, 13 (24\%) were withdrawn and 31 $(57 \%)$ were conceded. Of the 1572 appeals about the contents of the statements, about which parents would be appealing were they to be given this new right, $586(37 \%)$ were decided, $983(62 \%)$ were withdrawn and 3 (1\%) were conceded.

\section{Gender}

The policy will have a greater impact on boys rather than girls simply because more boys are identified as having SEN and disabilities than girls. In January 2009152,590 boys in primary, secondary and special schools had SEN statements - figures for statemented children are used as this is the potential field for the right to appeal under these proposals - $(72 \%$ of all children with statements) as opposed to 58,380 girls (28\%).

\section{Ethnicity}

In January 2009 the percentage of pupils in primary, secondary and special schools with SEN statements identified as White British was $75.7 \%$. 3.5\% were identified as of mixed background, $4.8 \%$ as Black, Black Caribbean, Black African or other Black background and $7 \%$ as Asian, including Indian, Pakistani, Bangladeshi or other Asian background.

Overall the impact on Non-white British ethnic groups is less than that for gender, though the research, referred to above, carried out for the DCSF in 2006 by the University of Warwick found that significant over- and underrepresentation of different minority ethnic groups relative to White British pupils remains. Black Caribbean and Mixed White and Black Caribbean pupils are around $1 \frac{1}{2}$ times more likely to be identified as having Behavioural, Emotional and Social Difficulties (BESD) than White British pupils, Bangladeshi pupils were $2-2 \frac{1}{2}$ times more likely to be identified as having Profound and Multiple Learning Difficulties (PMLD) or Sensory Impairment and Irish Traveller and Gypsy/Roma pupils (though a small number in total, which makes interpretation unreliable) were over-represented in most types of SEN. Asian and Chinese pupils, on the other hand, tended to be underrepresented in the areas of Moderate Learning Difficulty (MLD), SLD or Autistic Spectrum Disorder (ASD). 


\section{Challenges and opportunities}

Statistics produced by the First-tier Tribunal for 2007-08, show that, of the number of appeals registered - 3392 - a low percentage $(4.3 \%)$ were registered by parents of Black Caribbean, Black African or Other Black pupils and $2.4 \%$ by parents of Indian, Pakistani or Bangladeshi pupils (NB: $24 \%$ of cases registered did not disclose information about ethnicity). This proportion on Non-white British appeals is mirrored by that for appeals under the Discrimination Act, where over $90 \%$ of claims were made in respect of White British pupils (24\% again did not disclose information on ethnicity). Further breakdown of ethnic background is not available, nor is information about gender.

The low proportion of appellants from ethnic backgrounds may be due to perceived views about the bureaucracy and expense of the appeals process. In $2007-08,22 \%$ of parents employed a legal representative at the hearing (though there is no requirement to do so) and $16 \%$ had legal representation throughout the process.

\section{Equality impact assessment}

All the reforms coming from the Lamb Inquiry are predicated on improving services for children with SEND. In this case the policy has the clear potential to have a positive impact by reducing and removing barriers and inequalities that currently exist.

Impact on equality will not be significant overall because of the low numbers involved. The 3,392 appeals registered with the Tribunal in 2007-08, represented only about $1.5 \%$ of all pupils with SEN statements.

It is not expected that this change in the legislation will result in many more appeals being registered at the Tribunal, though can be anticipated that there may be a small increase - perhaps $5-10 \%$ - in the number of appeals about the content of the statement.

Amending the law as proposed will help increase the confidence of parents by closing a legislative gap and signalling the Government's willingness to address the issue. It should be seen in the context of the Lamb Inquiry as a whole, other recommendations of which will have the intention of reducing the number of appeals to the Tribunal overall.

The proposals will have some positive impact on boys and over-represented ethnic groups identified as having particular types of SEN or disability.

Moreover, it will provide a new avenue of redress where a local authority has decided not to amend (or update) an SEN statement. An out-of-date statement will clearly not provide what children need.

\section{Next steps}


Provision of information to the Tribunal on the ethnic background of appellants is voluntary, but we will be working with the Tribunals Service to monitor the take-up of the new right of appeal to see if there is any evidence that the measure impacts differently on ethnic minority groups as evinced in the its annual statistical reports. The overall effect of the policy will be reviewed, in conjunction with the Tribunals Service/Ministry of Justice, three years after coming into effect. 


\section{Power to provide Community Facilities}

In the White Paper 'Your child, your school, our future: building a 21st century schools system' (published 30 June 2009), the Government set outs its vision for the role of the school in preparing every child to make a success of their life and to break the link between deprivation and low achievement. A central element of this vision is that governing bodies should take some responsibility for pupils in the area more widely and should serve the wider community. Schools will achieve this by offering a wider range of opportunities and to improving access to specialist facilities, particularly by working in partnership with other schools and services.

To help to drive greater provision by schools of services to other pupils and the wider community, we want to place a duty on them to consider annually whether, and if so how, to exercise the powers they have: to provide facilities or services for the benefit of children at the school or their families; and to people who live or work in the locality in which the school is situated. The proposed amendments also remove financial barriers (subject to a new regulation power that can impose restrictions on the way money is used.)

The challenges of the 21st century will demand more from children and young people than ever before. They need higher levels of qualifications and skills suitable for the workplace and global economy if they are to become productive and happy citizens tomorrow. However, market failures and private choices do not always mean that the education and children's services system yet best serves the needs of all families - particularly the most vulnerable. Given the positive externalities not only to the young people themselves but also to wider society, this amendment to drive greater provision of community facilities and remove funding restrictions will enhance the experience and opportunities available to children and young people and thus contribute to improved outcomes and life chances.

The main objective of this policy is to increase the likelihood that schools will choose to use their existing power to provide community facilities.

\section{Challenges and opportunities}

\section{Disability}

\section{Challenges:}

'Feedback from both schools and pupils indicates that special schools are less confident that their extended schools activities meet needs, and children with SEN or a disability are more likely to rate the activities at their school as poor' (Wallace, Smith et al; 2009).

\section{Opportunities:}

$91 \%$ of extended schools are providing disability/SEN support professionals (Wallace, Smith et al; 2009). This shows that taking this approach could mean that pupils with disabilities are likely to get specific professional support. 
'Identification as having Special Educational Needs is one of the two main predictors of achievement, and there is some evidence that the achievement gap between pupils with and without SEN is smaller in FSESs' (Cummings, Dyson et al; 2007).

'The use of school premises and facilities by a wide range of people, for example those with disabilities, and the opportunity to see adults undertaking a range of courses, can help to promote positive images of people irrespective of race, gender or disability' (DFEE Schools Plus: Building Learning Communities 1999)

\section{Ethnicity}

\section{Challenges:}

In some analyses there is a weak relationship showing poorer performance for Asian pupils in FSES (Cummings, Dyson et al; 2007)

\section{Opportunities:}

'In some analyses a weak interaction between FSES and ethnicity is present. This represents a somewhat better performance for Black pupils in FSESs' (Cummings, Dyson et al; 2007)

'Making school premises available for mother tongue teaching and culture is one of a number of positive steps schools can take to forge stronger links with ethnic minority communities and build on curriculum activities' (DFEE Schools Plus: Building Learning Communities 1999)

\section{Gender}

\section{Opportunities:}

Overall, the difference in attainment at $5+A^{*}-C$ at GCSE or equivalent by gender has dropped slightly from 2005 , when it was 10.1 percentage points, to 9.6 percentage points in 2006 and now to 9.1 percentage points in 2007 (DCSF: Attainment by Pupil Characteristics, in England 2007/08)

\section{Equality impact assessment}

From the evidence set out above, we anticipate that this policy will have a positive impact on equalities in terms of disability, ethnicity and gender; and the more that schools embrace this direction of travel, the greater that benefit will be.

Although there has not been a specific pilot of the proposed changes, given that the existing legal framework is more limited. The policy is effectively an extension of the existing DCSF policy for schools to offer 'Extended Services'. Already over 80 percent of all maintained schools offer Extended Services, which means that they work with their local authority, other schools and private and voluntary providers to provide access to a core offer of extended services. Those services include a varied range of activities, including study support activities in a safe place to be for primary and secondary schools; childcare $8 \mathrm{am}-6 \mathrm{pm}, 48$ weeks a year for primary schools; parenting and 
family support; swift and easy access to specialist health and social care services such as speech and language therapy; community use of facilities including adult and family learning and ICT. These services will often be provided beyond the school day but not necessarily by teachers or on the school site. There is good evidence that this approach has been positive in terms of equality.

The Full Service Extended Schools Initiative (Cummings, Dyson et al; 2007), was a group of full service extended schools which acted as 'pathfinders'. The experiences and success of these and other schools have informed the core offer of services which it is expected will be offered by or through all schools, in partnership with local providers, by 2010. The evaluation of those pathfinders has been quoted above, and while DCSF recognises that not all schools will be delivering Extended Schools to the extent of those in the pathfinder, there is evidence that moving in this direction will be positive for improving equality in schools:

'The outcomes from FSESs have been positive in terms of impacts on pupils' attainment, personal, social and health outcomes for young people, family stability, community well-being and school performance. These effects have been strongest for children, young people and adults facing difficulties. Larger-scale effects are not yet evident but it is possible to envisage circumstances in which they might materialise' (Cummings, Dyson et al; 2007).

\section{Next steps}

We will consider whether it would be beneficial to build on existing nonstatutory guidance on providing access to extended services, by providing guidance to schools to support them in performing the duty to consider annually whether, and if so how, to exercise the powers they have: to provide facilities or services for the benefit of children at the school or their families; and to people who live or work in the locality in which the school is situated. If this is taken forward, it could include some further practical examples of how schools can meet this duty, and by including specific examples which promote equality, this guidance will also support Governing Bodies to meet their existing legal duty to promote equality, specifically in terms of ethnicity, gender and disability. 


\section{Extending the powers of maintained governing bodies to propose new schools; offer advice to or sponsor Academies}

To allow the governing bodies of strong maintained schools (that are accredited providers), in that capacity, to propose a new maintained school or sponsor an Academy. Currently, school governing bodies do not have the power to do this directly, but must set up either a separate Trust or a Schools Company, and be clear that they are acting as individuals, in order to achieve this. A number of school governing bodies have followed these arrangements successfully, but it is not as effective as it could be in fulfilling the Your Child, Your Schools, Our Future White Paper commitments. The legislation will also empower all maintained governing bodies (other than the governing body of a maintained nursery school) to provide advice and assistance to Academies.

The powers of governing bodies are set out in Schedule 1 to the Education Act 2002 which provides that they have power to do anything necessary or expedient for the purposes of or in connection with the conduct of the school (their existing school). We think that it is not clear whether or not governing bodies have the power to establish new maintained schools or be members of foundations of Trust schools. The legislation will clarify the position on both issues.

The White Paper also gave a commitment to address this by extending the powers of governing bodies, thereby removing this potential barrier to them more readily providing support and spreading good practice.

\section{Specific evidence for these provisions}

The main objective of this policy is to support school improvement by making it easier for maintained schools that have the right combination of educational excellence, capacity and track record and, therefore, meet the requirements for accreditation to be brought in to lead school improvement interventions in weak schools through Academies, majority Trusts and federations; and also to propose to establish new maintained schools.

There is evidence that local authorities can sometimes be reluctant to intervene in poor-performing schools at an early stage before an Ofsted inspection has placed a school in a category of concern. The Academies programme has been running for a number of years now and the evidence there (GCSE results; Key Stage 3 results; and independent reports by the National Audit Office, PricewaterhouseCoopers and Ofsted) show that they are working.

The National Audit Office report found that GCSE performance is improving faster in Academies than in other types of school. Taking account of pupils' personal circumstances and their prior attainment, Academies' GCSE performance is substantially better, on average, than other schools. They also said that Academies were on course to deliver value for money. 
The 2008 PwC report said that Sponsors contribute significantly to school improvement and that Leadership and governance is very good in Academies

They also said that in general, standards in Academies are rising at a faster rate than national average and against comparison schools and that there was no evidence that Academies have negative impact on neighbouring schools in terms of pupil profile.

GCSE results: For those Academies with results in 2008 and 2009 the increase in the proportion of pupils achieving at least five GCSEs at $A^{*}-C$ including English and maths is 5.0 percentage points, an increase on last year's Academy improvement rate of 4.3 percentage points. This is double the average national increase.

According to our data, the percentage of FSM pupils gaining $5 A^{*}-C$ including English and Maths increased $5.3 \%$ points between 2007 and 2008 . More than double the national improvement rate of $2.4 \%$ for FSM pupils nationally.

Comparing the 101 Academies with results in 2009 to their predecessor schools in 2001, there has been a 16.4 percentage point improvement in the percentage of pupils achieving $5+A^{*}-C$ (including English and Maths) from $17.8 \%$ in 2001 to $34.2 \%$ in 2009 . This compares to an 11.9 percentage point improvement nationally from $38.8 \%$ in 2001 to $50.7 \%$ in 2009 .

\section{What the evidence shows - key facts}

We do not consider that this policy will impact negatively on disability, ethnicity or gender. In so far as this policy supports that for Accredited Schools Providers/Groups (please see separate chapter) this policy is intended to have a positive impact for all pupils, regardless of disability, ethnicity and gender.

This policy will also allow suitable governing bodies to propose new special schools, so this may realise some positive benefits for people with disability.

\section{Challenges}

We do not think there are any particular risks associated with this policy as it is simply providing a mechanism to help share and spread proven good practice. For the key policies that this policy supports there are perhaps risks that schools may focus on the strongest performing pupils and 'teaching to the test' in order to demonstrate improvements as quickly as possible. However, we believe that the system provides sufficient checks to make sure this is not the result, e.g. using the new strengthened role of SIPs and the school's development plan.

\section{Opportunities}

We consider this policy has great potential to support other key policies in making a positive impact for all pupils. It will make it much easier and more 
straightforward for good schools to do more to support weaker schools. This in itself should lead to greater equality in education provision as schools will no longer work in silos where the strong continue improving and the weak are left to struggle. This broader approach means strong schools will share existing good practice with weaker schools to help them improve.

Removing unnecessary bureaucracy and the costs associated with establishing a Trust or Schools Company should result in more governing bodies of strong schools coming forward to support weaker schools; support or sponsor Academies; propose new schools. For those governing bodies that want to propose a new school or sponsor an Academy a key part of accreditation will be a proven track record of being outstanding in promoting equality. Ofsted's new limiting judgements regime will support this as schools will be under increasingly rigorous scrutiny on equalities. This, when coupled to the other key policies of local authority interventions and Accredited Schools Providers/Groups will result in improved levels of attainment and subsequently life chances for all pupils, particularly those who attend some of the most challenging schools. It will also help to contribute to progress on the National Challenge, ensuring that no school is below the $30 \%$ floor target in 2011.

\section{Equality impact assessment}

A positive impact is explicitly intended and very likely.

This policy is intended to make it much more straightforward for the governing bodies of maintained schools that have the right combination of educational excellence, capacity and track record (and are, therefore, accredited under the Accredited Schools Provider/Group arrangements) to support the local authority interventions and School Improvement policy, by enabling them to be more readily brought in to lead school improvement interventions in weak schools through Academies, majority Trusts and federations, and also to spread existing good practice by proposing new maintained schools.

\section{Next steps}

This specific policy should not have a negative impact on disability, ethnicity or gender. When considering this policy in connection to the linked policy of a system of accreditation for schools who want to propose new schools or sponsor Academies, there will be a clear positive impact. Only those governing bodies with a proven track record in promoting equality will be allowed to be involved in the establishment of new maintained schools and Academies. When updating guidance to take account of the new policy, we will take the opportunity to reinforce messages around equality responsibilities. 


\section{School Improvement Partners (SIPs)}

Since 2004 local authorities have been required to ensure that every maintained school (primary and secondary) has a School Improvement Partner (SIP). The intention was for the SIP to act as a professional critical friend to schools, helping to build leadership capacity in the school's leadership team. The role has focused on the school's self-evaluation, leading to the agreeing of priorities and targets to improve pupil attainment, attendance and behaviour.

The White Paper Your child, your schools, our future: building a $21^{\text {st }}$ century schools system sees the role of the SIP defined more clearly so that SIPs are not only responsible for monitoring and challenge, but also to provide schools with support to improve on all Every Child Matter (ECM) outcomes for children, brokering in school improvement support, making decisions about schools' specialist status and having increased leverage over weaker performing schools. This new enhanced role sees SIPs having a much more focused role clarifying their position as the intermediary between schools and their local authority.

\section{Specific evidence for these provisions}

The purpose of this policy is to ensure that schools have the ability and the capacity to provide the best possible education for all of its pupils, and to ensure the outcomes and life chances of all of its pupils are increased.

However the most recent external evaluation (The New Relationship with Schools (NRwS) Evaluation, carried out by York Consulting for DCSF Published August 2008), identifies that the direct impact of the SIP programme on school standards and quality is more difficult to establish due to the nature of the role which is to challenge and support rather than engage in school for improvement directly. Nevertheless, it does highlight a small number of evaluation case studies which indicate a link between SIP support for school improvement interventions and better school outcomes.

\section{What the evidence shows - key facts}

Despite the improvements that have been made on pupils' attainment and achievement over the last 10 years, many children who fall into the categories of disadvantaged or vulnerable groups fail to fulfil their potential, leading to variations in educational outcomes. The proposals for the reformed SIP programme intend to help schools to focus more acutely on narrowing the gaps in educational outcomes for all of its children.

\section{Challenges and opportunities}


The reformed role of the SIP has great potential for all of the above groups.

SIPs will no longer just advise schools and suggest what improvement support is required - they will now be expected to broker in that support. Schools who are not supporting any one or all of above groups effectively will receive greater challenge as well as support to ensure that no child is left behind.

SIPs will be expected to ensure that where a school is underperforming they agree and sign off the school's improvement plan, and will have the power to hold back a proportion of the school's budget until an adequate plan which addresses all of the concerns raised is agreed. This will force schools to address the needs of all pupils and not just focus their attention on those considered the strongest group and more likely to succeed - improving the quality of school improvement and ensuring every pupil gets to attend an excellent school.

The proposed national register will ensure future SIPs are matched and placed in schools where they have the greatest impact and are suited to working with that type of particular school. For example a school facing challenging circumstances, such as a high proportion of pupils on or eligible for Free School Meals (FSM) or schools located in areas of high deprivation.

\section{Equality impact assessment}

A positive impact is explicitly intended and very likely.

The reformed role of the SIP will be much broader and inclusive and will cover all five ECM outcomes. The reforms adds weight to the role in line with that of the National Challenge Adviser (NCA) and City Challenge Advisers (CCA) bringing equality to all categories of schools that SIPs will serve. These reforms will in turn contribute to ensuring all children and young people receive an excellent education.

Through consultation we will ensure that we analyse very closely any evidence of inequality issues that may arise and feed into the policy development as appropriate. The SIP role will include helping schools to set realistic and challenging targets for BME and FSM groups - helping to narrow the achievement and progression of these identified groups.

\section{Next steps}

The joint DCSF and National College consultation on SIPs is currently underway, and is open to schools, local authorities, other agencies, Non Departmental Agencies (NDPBs) and other delivery partners. The consultation focuses on the proposals set out in the White Paper, in particular, the widened role of the SIP. The consultation is seeking the views from the wider school improvement community on the issues relating to segmented schools and accrediting SIPs to support these schools. As well as this, the 
conultation will explore the barriers surrounding the brokerage role. This is particularly significant, as it is the brokerage role of identifying and developing the support required to bring about sustained improvements, which has the greatest potential to have the most impact on the identified groups, and evidence shows that currently this is a role that SIPs do less well.

We will issue guidance, where we will make it clear the role of the SIP on challenging schools on attainment gaps and brokering in the relevant support to help them bring about change. 


\section{Development of a School Report Card}

The School Report Card is being developed as part of the Government's intention to improve how schools' performance is reported to parents, communities and other stakeholders providing clear and comprehensive information. The School Report Card will build on the New Relationship with Schools, further streamlining the accountability system.

We will engage with stakeholders through two years of piloting beginning Autumn 2009. At the core of the pilot will be a substantial sample of schools who will work with us in ensuring the underlying systems produce timely accurate data and contribute to the development of the information that underpins the Report Card and how it is presented

\section{What the evidence shows - key facts}

Much information is already published about schools' performance, e.g. in the Achievement and Attainment Tables, Ofsted inspection reports, the School Profile and school prospectuses. The Tables do not report schools' success in raising the attainment of pupils from disadvantaged backgrounds so that they have the same opportunities in life as their more advantaged peers.

Husbands et al. (2008) of the EPPI Centre conducted a review of accountability and children's outcomes in high-performing education systems. The study confirms the widespread use of outcome indicators for accountability purposes, although the nature and purposes of these functions varied markedly between systems. Educational indicators were used for monitoring schools and national standards. They were sometimes used as a means of holding individual schools and the education system to account; they also informed the development of policies, as well as school and area improvement.

\section{Challenges and opportunities}

Reducing disadvantage is concerned with measuring a school's success in raising the academic attainment of disadvantaged and vulnerable groups of pupils relative to their peers, while still improving the outcomes for all children. The school accountability system will now focus more sharply on how well each child is progressing and developing; it will take more account of the views of pupils and parents; and reward those schools which are most effective in breaking the links between deprivation and low achievement. We believe that the introduction of the School Report Card will make the school accountability system more coherent, better co-ordinated, more streamlined and better able to recognise the full range of each school's achievements by:

- Closing the gap in educational achievement for children from disadvantaged backgrounds 
- It should be equally possible for a good school serving a disadvantaged community and a good school serving a less disadvantaged area to obtain a high score on the School Report Card

- $\quad$ During the forthcoming pilot year, we intend to develop indicators which capture the extent to which schools have been successful in ensuring that the gaps between the attainment of disadvantaged and vulnerable groups is reduced.

- The proposed indicators for narrowing gaps in pupil performance category along with pupils' progress will measure how well a school enables every child to reach its potential.

- $\quad$ The indicators we propose to use to measure the Narrowing Gaps in Pupil Performance category are designed to specifically address underperformance correlated to poverty or ethnicity: The definition of a disadvantaged pupil included in the Narrowing Gaps in Pupil Performance category will be the same as that used in Regulations that came into force on 31 December 2008 requiring Local Authorities to set targets for eight 'under-performing groups'. These groups are: Black Caribbean; White/Black Caribbean; Black African and White/Black African; Black Other; Pakistani; White Other; Gypsy, Roma and Traveller of Irish heritage; and, Children eligible for free school meals

- We believe that some form of CVA is the best means of contextualising Pupils' Progress. Contextualised VA measures not only take into account a pupil's prior attainment, but also other contextual factors known to have an effect on their progress that are outside a school's control - for example, their gender, degree of deprivation, Special Educational Needs, first language, ethnicity However, in light of the concerns raised in the consultation about CVA, we will review the factors that should be taken into account and the methodology used to calculate scores during the pilot phase.

- We are committed to the SRC containing a measure which reflects schools' success in securing positive outcomes for children with SEN, as well as reflecting the views of pupils with SEN and their parents. The evidence points to using measures which: focus on the progress of the lowest achievers, the majority of whom are identified as having SEN; considering how the reducing disadvantage measure could be used; and separating out satisfaction results for pupils with SEN and disability and their parents, and comparing them to other pupils and parents.

- $\quad$ By reporting all the underpinning performance data on the School Report Card, different users will still be able to look at the particular aspects of performance that interest them most - identifying areas of a school's work that are particular strengths; or areas in a strong school that continue to need improvement. For example:

- Focus on an increase on the take up of STEM subjects by girls

- See improvement of confidence of girls in STEM subjects

- Evidence that boys reading is improving

- $\quad$ Ofsted grading will be on front page of Report Card and we are exploring the option of including the grade on which the school promotes equality and tackles discrimination amongst others. 


\section{Equality impact assessment}

A positive impact is explicitly intended and very likely.

The school accountability system as set out in the White Paper will now focus more sharply on how well each child is progressing and developing; it will take more account of the views of pupils and parents; and reward those schools which are most effective in breaking the links between deprivation and low achievement. To deliver this we will develop a new School Report Card (SRC) for every school, which will provide a rounded assessment of school performance and enable parents and the public to make better informed judgements about the effectiveness of each school.

We believe that the introduction of the School Report Card will make the school accountability system more coherent, better co-ordinated, more streamlined and better able to recognise the full range of each school's achievements

\section{Next steps}

We intend to pilot the proposals set out in the School Report Card prospectus over the next two years starting in September 2009.

At the heart of the pilot will be a substantial sample of schools who will work with the DCSF to ensure the underlying systems produce timely, accurate data and contribute to the development of the information that underpins the Report Card and how it is presented.

The first pilot phase commences in autumn 2009 to develop the performance indicators which might be used in the Pupils' Attainment, Pupils' Progress, and Narrowing Gaps in Pupils' Performance categories, and exploring the weightings to be used to produce a score for each of those categories focusing on education outcomes.

We will also test options for contextualising the School Report Card including information on disability, gender and ethnicity.

The second pilot phase commences in autumn 2010 focus on wider outcomes- wellbeing and parent/pupil survey data building on the results from the first year.

We will also test options for reflecting a school's work with disabled children and children with Special Educational Needs.

The results of the pilots will be published at regular intervals throughout the next two years. 


\section{Data Collection - Wales (the All Wales Core Data Set)}

In Wales, current legislation enables the collection and publication of a range of information about maintained schools and individual pupils receiving funded education, either at a maintained school or arranged and funded through the Local Education Authority. However as we expand the scope of our policies on the role of data to support self evaluation and to support safeguarding of young people we believe legislative change will be necessary to ensure that we are able to collect the most appropriate information from all forms of provision. In particular additional information will be necessary to support local authorities the discharge of new duty under section 436A of the Education and Inspections Act 1996 (Duty to make arrangements to identify children not receiving education) inserted by section 4 of the Education and Inspections Act 2006.

The School Effectiveness Framework (SEF) is the overarching policy which brings coherence to work aimed at improving the education and wellbeing of our school-aged learners in Wales.

The SEF aims to improve overall pupil achievement, reduce variation in achievement within and between different groups of pupils, schools and local authorities, and diminish the link between socio-economic circumstances and pupil/school attainment.

To support the SEF, DCELLS is developing a balanced suite of contextual analyses, consistent across Wales, supported with guidance and training, to support school self evaluation and performance improvement. Data packs will present schools' performance and progress in context, support the work and principles of the School Effectiveness Framework and aligning with the Estyn 2010 Inspection framework.

The provision of standard data packs for primary and secondary schools will support them in evaluating their progress, evaluate the progress made by different groups of pupils within schools and authorities, identify strengths and weaknesses and offer opportunities to learn and share best practice. Overall the intention is that the data sets will promote and support continuous improvement and

A key focus of developing DCELLS policy, mirrored by Estyn in their new 2010 Inspection Framework, is an increased focus on the importance of pupil wellbeing as a key factor in effective schools. Policy is in early days of development in relation to how we might measure wellbeing but it is central element of the School Effectiveness Framework.

Current legislative provision does not enable the Welsh Ministers to collect information on the views of parents and pupils about schools or alternative educational provision funded under section 19 of the Education Act 1996.

Current legislative provision does not enable the Welsh Ministers to require provision of information from the widest range of provider. Pupils receiving 
education through alternative provision do not always achieve as well as those in the maintained sector. It is important that we challenge these providers to ensure that individuals receive the highest quality provision.

\section{Specific evidence for these provisions}

Statistics relevant to Wales are available at; http://wales.gov.uk/topics/statistics/headlines/schools2009/hdw200903241/?la $\underline{\mathrm{ng}=\mathrm{en}}$

The Welsh Assembly Government is committed to improving the education and wellbeing of our school-aged learners.

The School Effectiveness Framework (SEF) is based on the principles of trilevel reform - that is, Government, local authorities and schools working collaboratively to bring about systems change. The SEF is the Welsh Assembly Government' $s$ vehicle for taking forward this commitment by aligning policies and their implementation to secure better outcomes.

Detail relating to the SEF and the role of data and accountability frameworks within the SEF and to help raise standards are in the public domain at;

http://wales.gov.uk/topics/educationandskills/publications/guidance/schooleffe ctivenessframework/?lang=en

\section{What the evidence shows - key facts}

There is a significant variation in educational outcomes within and between groups of children, frequently associated with their social and economic circumstances. As a consequence many children, often concentrated into particular disadvantaged or vulnerable groups, fail to fulfil their potential.

Much information is already published about schools' performance, e.g. in Governors' Annual Reports and School Prospectuses. Additional information is provided by Welsh Assembly Government and Local Authorities to support schools in effective self evaluation and target setting. These sources do not specifically report schools' success in raising the attainment of pupils from disadvantaged backgrounds so that they have the same opportunities in life as their more advantaged peers.

Estyn remit report on Use of performance data in Local Authorities and schools (Feb 2008) found that whilst all Local Authorities made use of data and evidence to support improvement there was substantial duplication across authorities not all analysed data sufficiently for all schools. They found wide variation in schools understanding and use of data and that not all used made approaptie use of data to assess the performance of specific pupil groups and to support self evaluation and continuous improvement. 
A host of international evidence has been published on the topics of use of targets, indicators and various accountability models to promote educational improvement. DCELLS does not wish to move to a high stakes accountability and 'league table' approach but does wish to consider, in the light of international evidence, how it can effectively use performance measurement, within a self evaluation framework to improve outcomes for all learners.

\section{Disability:}

- In Wales in 2008, 9.6 per cent of 15 year old pupils with a statement of special educational needs gained the Level 2 Thresholds (equivalent volume of learning to five or more GCSE grades $A^{*}-C$ ), compared with 57.4 per cent of those without such a statement (SB 16/2009).

\section{Ethnicity}

- $\quad$ Some ethnic background cohorts are very small in Wales and as such comparison of outcomes needs to be carried out with care as results for such small groups will show more volatility year on year than for larger groups of pupils.

- $\quad$ However, there are clear variations in the performance of pupils from difference ethnic backgrounds with pupils from Chinese or Chinese British backgrounds achieving higher than other groups and those from black ethnic backgrounds achieving below other groups (SB 16/2009).

\section{Gender}

- In line with most other developed nations girls in Wales out perform boys across the curriculum and across the key stages. The widest gaps in attainment are at key stage 3 although the gap then narrows as young people complete their compulsory education. The gap is at its largest for English and Welsh first language and narrower for mathematics and science (SB 16/2009).

- Small fluctuations in the overall pattern and degree of boys' underachievement do not impact on the overall, persistent pattern.

\section{Challenges and opportunities}

The Welsh Assembly Government aims to measure a school's success in raising the academic attainment of disadvantaged and vulnerable groups of pupils relative to their peers, while still improving the outcomes for all children. The School Effectiveness Framework, supported with strong self evaluation, will focus on the right of each and every young person to a high quality learning experience throughout their educational journey. The SEF will enable the system to track the progress of each young person along their route through each of his or her educational settings and schools. Such a construct flows from the seven core aims for young people (attached). It enables children's progress to be monitored as an individual and removes the tension 
of judging institutional performance as a proxy for pupil performance. This also means that within-school variation, school- to- school variation and local authority performance can be assessed, supported and challenged but always in the context of performance of individual children within a local authority area, not individual institutions.

The initial Core Data Sets currently being released to schools already provide analyses of gender performance differentials and a focus on attainment of pupils from disadvantaged backgrounds. The introduction of a statistical family, whereby schools can consider their performance in relation to that of other schools working in similarly challenging circumstances ${ }^{2}$ will facilitate the sharing of best practice where others have seemingly better overcome those challenges. Further development of the All Wales Core Data Set and the planned accompanying interactive tools will better enable schools to focus on a wider range of learners to identify their strengths, weaknesses and areas of development to the benefit of all learners.

The All Wales Core Data Set has been developed with significant partnership input from Estyn who are committed to its use as part of the 2010 Inspection Framework.

\section{Equality impact assessment}

A positive impact is explicitly intended and very likely.

We believe that the development of Core Data Sets and introduction of statistical families will support the core principles of the Schools Effectiveness Framework and help schools to secure continuous improvement and to target resource more effectively to support identified areas of weakness or learner groups not achieving as well as might be envisaged.

\section{Next steps}

The first issue of data packs has already been issued to schools. Stakeholder engagement is being strengthened with the aim of increasing awareness and skills to interpret as well as to identify where the approach requires refinement.

Further, more formal, stakeholder feedback events are scheduled for February 2010 following which necessary modifications to the data sets and family groupings will be agreed and taken forward.

An online, interactive tool to provide more 'fine tuned' analysis of data is being developed alongside this work. This will also build on improvements in data collection for children educated other than at school enabling better monitoring and support for this vulnerable group.

\footnotetext{
${ }^{2}$ Statistical families have been derived on the basis of linguistic delivery model, size of schools (primary sector only), proposition of pupils entitled to FSM, living in the $20 \%$ most disadvantages areas according to the Welsh Index of Multiple Deprivation, with SEN and from an Ethnic Minority background
} 
Improvements in data quality, for ethnicity coding, home language, language acquisition skills and support for learners with SEN will also feed through in to improved analyses for these pupil groups. 


\section{Warning Notices and Accredited Schools Groups}

Every pupil deserves a world-class education delivered by world-class teachers. Currently, too many pupils are not receiving this offer and are as a consequence not reaching their full potential. This is a wasted opportunity not only on a personal level, but also for the economy and society more generally. We expect Local Authorities (LAs) to support and challenge schools to ensure that they tackle under-performance quickly and effectively. Many of these schools require a great deal of support from LAs and partners to improve, and LAs may therefore need to commission support for them. But where LAs fail, or are unwilling, to do this in a timely and decisive way, the Government must be able to act quickly to ensure that appropriate action is taken so that failure does not become entrenched. That is what all pupils deserve and parents are entitled to expect.

The Schools White Paper outlines our plans to expand and strengthen our apporach to ensure that all schools realise they can and should improve and that they are responsible for their own improvement. This policy aims to ensure that intervention in schools happens well before the school needs to be placed in an Ofsted category, or the school is under-performing significantly. The Children's, Schools and Families Bill will introduce a new power that will enable the Secretary of State to direct a local authority to issue a warning notice to a school where standards of pupil performance at the school are unacceptably low.

Where it is agreed that is approriate that a structural solution will be most effective at securing the rapid and sustainable improvement needed, local authorities will be able to select a partner from an agreed list of Accredited Schools Groups (ASGs). High performing educational institutions have the potential; track record and capacity to provide support through a long-term commitment to underperforming schools. Accrediting schools groups with a high performing lead partner will enable local authorities to more easily choose an appropriate high quality consortium, which will ensure improvement in the underperforming school through an Academy, majority trust, federation or amalgamation, through the accredited schools group.

\section{Specific evidence for these provisions}

The main objective of this policy is to ensure that every child receives an excellent standard of education, and that no child should be disadvantaged from achieving that. This includes that no child should be disadvantaged from this due to their parents' level of education or the area in which they live; disability; gender; age or faith. A disproportionate number of pupils from target groups are represented in underperforming schools.

There is evidence that local authorities can be reluctant to intervene in poorperforming schools at an early stage before an Ofsted inspection has placed a school in a category of concern. 
The Office of the Schools Commissioner seeks to ensure that local authorities offer excellent standards of education for all their young people - and choice and diversity is a priority. In brokerage of Academies and National Challenge Trusts - the goals of raising standards and ensuring choice and diversity are the key features of conversations with local authorities.

There is limited evidence of the impact of partnership working through longterm mechanisms because of the length of time that some of the programmes have been running. However, the Academies programme has been running for a number of years now. There is a growing body of evidence - GCSE results, Key Stage 3 results, and independent reports by the National Audit Office, PricewaterhouseCoopers and Ofsted - that shows Academies are working

The benefits of this approach are illustrated by the improvements seen in schools which have become Academies:

The National Audit Office report found that GCSE performance is improving faster in Academies than in other types of school. Taking account of pupils' personal circumstances and their prior attainment, Academies' GCSE performance is substantially better, on average, than other schools. They also said that Academies were on course to deliver value for money.

The 2008 PricewaterhouseCoopers report said that sponsors contribute significantly to school improvement and that leadership and governance is very good in Academies. They also said that in general, standards in academies are rising at a faster rate than national average and against comparison schools and that there was no evidence that Academies have negative impact on neighbouring schools in terms of pupil profile.

GCSE results: Following the 2009 GCSE results, the 63 Academies which have been open long enough to have results in both 2008 and 2009 have seen an increase of 11.7 percentage points in the percentage of pupils at the end of Key Stage 4 gaining 5 or more $A^{*}-C$ grades at GCSE and equivalent (up to $67.1 \%$ ). This is more than twice the increase seen nationally (maintained mainstream, Community and Technology Colleges and Academies) of 5.4 percentage points. If we include English and Maths, Academies have increased by 5.0 percentage points (up to $34.9 \%$ ) compared to 2.5 percentage points nationally.

According to our data, the percentage of pupils eligible for free school meals gaining $5 A^{*}-C$ GCSEs including English and Maths increased $3.4 \%$ points between 2008 and 2009 . This is $0.3 \%$ points more than the national improvement rate of $3.1 \%$ for pupils not eligible for free school meals

Comparing the 101 Academies which have results in 2009 to their predecessor schools in 2001 (the last year of checked data), there has been a 38.9 percentage point improvement in the percentage of pupils achieving 5+ $A^{*}-C$ from $26.3 \%$ in 2001 to $65.2 \%$ in 2009 . This improvement is nearly twice 
that seen over the same period nationally. Academies have also almost doubled the percentage of pupils achieving $5+A^{*}-C$ including English and Maths, going from $17.8 \%$ in 2001 to $34.2 \%$ in 2009 . Nationally the increase is 11.9 percentage points from $38.8 \%$ in 2001 to $50.7 \%$ in 2009 .

In addition, there is a large emerging body of evidence about the impact of partnership working to support school improvement. This is detailed in the Impact Assessment Main Document: Evidence Base.

\section{What the evidence shows - key facts}

Although 52 Warning Notices have been issued in the period up to the end of May 2009, at the end of the summer Term 2009 there were 193 schools requiring special measures and 167 requiring significant improvement (notice to improve). About $30 \%$ of future Ofsted failures are detectable by local authorities at least 12 months before inspection, giving the local authorities time to provide appropriate challenge and support to the school to prevent failure. This suggests that despite the large number of potential candidates, local authorities are reluctant to intervene quickly to prevent deterioration in school performance.

On average it takes a secondary school 20 months to come out of special measures, and on average it takes a primary or special school 18 months to come out ${ }^{3}$.

More broadly, some low-attaining schools have been stuck at unacceptable levels of performance for several years. For example, the 2009 validated data show 256 primary schools where Key Stage 2 level 4 attainment rates in both English and mathematics had remained below the Government's $65 \%$ floor target for four or more years (the data on the number of warning notices and numbers of schools in special measures/with notice to improve supplied by Ofsted). Most of these schools were not in a formal Ofsted category of concern; the majority had low contextual value added scores, suggesting that persistently low attainment cannot be fully explained by difficult local circumstances.

\section{Deprivation:}

In 2007 - 631 schools were below the National Challenge 30\% floor target. In 2008 - 440 schools were below the floor target (a net reduction of 191 schools). The latest validated results show that 247 schools were below the floor target in 2009.

207 schools rose above the floor between 2008 and 2009 58 schools fell below the floor between 2008 and 2009

\footnotetext{
${ }^{3}$ As at end August 2009
} 
Of the schools remaining below the floor 107 improved since 2008; 15 schools below the floor were "flat" e.g. same result in 2009 as 2008 and 46 declined.

\section{Schools under $30 \%$}

Figures show that 202 schools, or just under half are at $25 \%+$; and 330 schools out of the 440 are at $20 \%+$.

Of the 8 schools under $10 \%$ - We are now looking at structural solutions for all schools under 10\%. These structural solutions will impact where the governing body or senior leadership team is weak. We recognise that additional support is necessary and will provide for that.

Many of the schools below the floor target are in challenging circumstances: for example, many have higher than average proportions of pupils with special educational needs (SEN) or entitled to free school meals, and many are located in areas of high deprivation.

\section{Challenges}

We believe that there is a risk that local authorities may overlook the role of deprivation measured by pupils' eligibility for free school meals or by whether they have English as an additional language (EAL). The impact of receipt of free school meals particular on attainment remains adverse and stubbornly large for certain groups of pupils - Bangladeshi and white working-class boys. There may therefore be a risk of failing to deliver on the Every Child Matters commitment to ensure that all children achieve failing to improve the performance of these children.

There is also, in our view, a risk that schools with low overall levels of performance will seek to improve the overall attainment levels of their pupils by concentrating on the strongest performing groups/pupils in the years about to take Key Stage tests or GCSEs. At the extreme this might lead to deterring pupils from entering Key Stage tests or entering them for inappropriately low tiers at GCSE and that might disproportionately affect particular groups of pupils in key subjects- for example
a. at Key Stage 1 or boys in reading/writing,
b. at Key Stage 2 - Pakistani pupils in science,
C. and pupils with special educational needs at any Key Stage or at GCSE.

There is also a risk that schools will teach to the test to ensure that results improve while the schools are under close scrutiny. This will deliver good results for the school but will not equip pupils with the skills or understanding to progress to the next level (in education or training) or equip them with the skills for the world of work. 
We believe there are sufficiently strong counter-measures in place to mitigate these risks. The new strengthened role of School Improvement Partners (SIPs) - see separate chapter - will enable them to challenge schools to identify any poorly performing groups of pupils, and to monitor data to mitigate the risks outlined above. The school's development plan must as a minimum set out the school's amendments to its improvement plan to identify what support this group of pupils requires, how this additional support will be delivered, and how the effect of this additional support will be measured with reference to data collected on the pupils receiving support, and on the rest of the school's pupils. The plan will be signed off by the School Improvement Partner and local authority, and the School Improvement Partner will have the power to withhold a portion of the school's budget if the plan is not satisfactory or delivered in full.

\section{Opportunities}

This policy has a great potential to make a positive impact on the above issues, and is aimed at ensuring all young people have an excellent education - provided with the support of a high performing institution who manages equality issues well. Evaluations show that the Academies programme has had a positive impact on ensuring school improvement in some of the most underperforming schools (where we would expect pupils in general, and those from the particular groups above) to do less well than their peers who attend higher attaining schools.

By intervening earlier, we expect that some of these issues will be caught quicker, and that solutions for them and improvement in education and other services offered will be quicker. This will ensure that all pupils benefit from swift and decisive actions to raise standards of achievement in poorlyperforming schools, irrespective of their background or gender, ethnicity, disability or eligibility for free school meals.

This will result in improved levels of attainment and subsequently life chances of pupils who attend some of the most challenging schools. It will directly impact on the progress towards ensuring no school is under the $30 \%$ National Challenge floor target in 2011.

Using Accredited Schools Groups to run underperforming schools will ensure that existing effective policies on all of the above from the lead education partner are transferred to the underperforming school, and managed well.

\section{Equality impact assessment}

A positive impact is explicitly intended and very likely.

It is expected that the two elements of this policy (1. powers for the Secretary of State to issue Warning Notices where school performance is unacceptably low and 2. Accredited Schools Groups) will enable more rapid and sustainable improvement at some of the most poorly performing schools, which will 
contribute to all children and young people benefiting from an excellent standard of education.

\section{Next steps}

There will be analysis of information from those schools subject to Warning Notices for poor performance to seek qualitative data on:

- Improvements in pupil attainment at KS2 and GCSE for previously under-performing minority groups identified by ethnicity/gender/FSM, and ethnicity/gender/SEN (with or without FSM);

- Sustained progress of school measured against national/LA targets for under-performing groups of pupils identified by ethnicity and FSM; and

- Length of time taken for pupil performance amongst under-performing groups to improve.

We have commissioned a short external review of the effectiveness of the use of warning notices, and aim to publish the results in late 2009. We are also considering whether a full-scale evaluation of local authorities' use of their intervention powers should be commissioned.

When the extended powers come into force, there will be a constant evaluation of success of policy by Ofsted (who, as under current legislation, should receive a copy of each warning notice and maintain data) with school inspections, monitoring of schools categories and warning notice appeals; reports to LAs from School Improvement Partners (SIPs) and National Challenge Advisers, and National Strategies regional teams monitoring of LA support for schools causing concern. Ofsted inspections would also judge whether warning notices make any difference to the outcomes of pupils from under-performing minority groups.

Therefore, there is potential for evaluation here to test how this intervention leads to more positive outcomes for previously under-performing minority groups of children and young people.

We expect to accredit the first group of providers in Spring 2010.

We will annually monitor and evaluate the impact of the policy on:

o pupil attainment at GCSE for previously under-performing minority groups identified by ethnicity/gender/FSM, and ethnicity/gender/SEN (with or without FSM);

- improvements in outcomes in schools in Accredited Schools Groups measured against national/LA targets for groups of pupils at risk of under-performing; and

0 the length of time taken for pupil performance for groups at risk of under-performing.

We aim to have an external evaluation of the impact of this policy in September 2014, and will publish an interim review in September 2012. 


\section{Duty on Ofsted to Report on Provision for Pupils with Special Educational Needs and Disabilities as Part of School Inspection}

Section 5 of the Education Act 2005 sets out the general areas which must be covered as part of routine Ofsted inspections of maintained schools (and Academies and non-maintained special schools). The intention is to add to section 5 an explicit duty on Ofsted to report on provision for pupils with special educational needs and disabilities. This is in direct response to a recommendation made by Brian Lamb, chair of the Special Education Needs Consortium, as part of his Inquiry.

The duty on Ofsted will underpin and reinforce the changes that have already been made to Ofsted's non-statutory school inspection framework. The new framework, which took effect from September 2009, includes a strong focus on the experience and progress of different groups of children and young people, including those most likely to underachieve and the most vulnerable. In relation to pupils with special educational needs and disabilities, inspectors are expected for example to make a discrete judgement in every routine school inspection report on 'the quality of learning for pupils with special educational needs and/or disabilities and their progress'.

\section{Specific Evidence relating to these provisions}

Children have special educational needs (SEN) where they have a significantly greater difficulty in learning than their peers or a disability which prevents or hinders the child from accessing the mainstream schools in the area. Just over twenty percent of the school population has SEN at any one time. At January $20091,433,940$ pupils had SEN without statements $(17.8 \%$ of the school population) and 221,670 (2.7\%) had statements.

The evidence chapter, sets out a range of data relating to children with SEN, and demonstrates that they perform less well than their peers across a range of measures including attainment and exclusions.

\section{Equality Impact Assessment}

A positive impact is explicitly intended and very likely.

The proposed duty on Ofsted is intended to contribute to the Department's over-arching aim to improve outcomes for children with SEN and disabilities by narrowing the gap in attainment between children with SEND and their peers (DSO4).

In general terms the duty will impact more on boys than girls and 'White British' pupils more than other pupils due to a higher proportion of such pupils with SEN, although the duty will also impact on some ethnic groups that are over-represented in relation to particular types of SEND. However, the impact 
of the duty needs to be seen in the context of underpinning a set of inspection arrangements which are already in place and which give priority to this matter.

In addition, inspectors are already required under section 5 of the Act to report on 'how far the education provided in the school meets the needs of the range of pupils'. This requirement is reflected in the school inspection framework and evaluation schedule. Inspectors are expected to focus on the experience and outcomes of different groups of pupils including those related to gender and ethnicity. All inspection reports include a discrete judgement on the effectiveness with which the school promotes equal opportunity and tackles discrimination', which has a potential limiting effect on the overall effectiveness grade for the school. For example if a school is judged inadequate in terms of equalities the school will normally be found to be inadequate overall.

Overall, the policy is expected to have a positive impact in terms of equalities and will provide reassurance that the priority that is attached to SEND within school inspection now will be maintained in the future.

\section{Next steps}

To maximise the impact of this provision, Ofsted is enhancing its training arrangements so that school inspectors are provided with training on SEND on an annual basis. As part of its quality assurance procedures, Ofsted will regularly monitor inspection reports to check that the emphasis given to equalities, including outcomes for pupils with SEND and also other groups of pupils are appropriate. The impact of the duty will be reviewed a year after its introduction. 


\section{Reforms to the Primary Curriculum}

The policy will introduce a more flexible primary curriculum to allow schools to tailor teaching to meet the needs, interests and aspirations of all their children and help them make the best possible progress in literacy, numeracy and ICT. This new curriculum will also strengthen considerably the transition links between the Early Years Foundation Stage and Key Stage 1, and between Key Stage 2 and Key Stage 3.

In order that the development of the curriculum review was well informed by equalities stakeholder groups, an Equalities Reference Group was established. It was composed of members of such organisations as National Society for the Prevention of Cruelty to Children, the Equalities and Human Rights Commission, the UK National Autistic Society, the Interfaith network and many more.

A number of seminars were held on Equalities in the Primary Curriculum Review which included teachers and head teachers from Severe Learning Difficulties/Profound and Multiple Learning Difficulties schools, an Emotional, Behavioural and Social Difficulties school and a Royal National Institute for the Blind school.

Participants at the equalities seminars during the review of the new design framework felt that the new curriculum model was inclusive because:

- it starts with the child at the centre rather than content

- it emphasises skills and attitudes rather than only mastering knowledge

- it allows children to progress along the same route, albeit at different rates and stages.

It was felt important that inclusion was reflected in the language used in the Programmes of Learning so that schools would feel it was relevant to them and their children e.g. some use of the term 'communication' rather than 'speech' to show there was a range of ways of communicating.

\section{Specific evidence for these provisions}

Disabled pupils experience inconsistencies in the provision of support and curriculum resources. For example, good deployment of teaching assistants can be the critical factor in inclusive learning, but can equally distance pupils from teaching and learning. (DRC literature review 2005)

A key finding from research commissioned to identify the priorities of disabled children and young people for the Secretary of State's report on progress towards disability equality was that many disabled young people felt that they were not reflected within the curriculum. 


\section{Challenges and opportunities}

The new primary curriculum has a great potential to make a positive impact on equalities, which should be dealt with across the whole curriculum and not consigned to particular areas of learning. The consultation will offer an opportunity to explore some of the equalities issues touched on in this document in more detail and there will be further assessment of the impact on equalities in the light of comments received.

The purpose of the policy is to provide a curriculum that is broad, balanced and accessible. A high quality and more flexible curriculum will to allow teachers to address individual pupils' needs and prepare them for changes in national and global contexts.

The changes to the primary curriculum will allow schools greater flexibility and increase the benefits to children of personalised learning. Children will not be forced into a "one size fits all" prescriptive curriculum which lacks coherence or relevance for the child. Personalised learning helps to narrow gaps and raise achievement for all. (2020 Vision: Report of the Teaching and Learning in 2020 Review Group)

Teachers will be enabled to design a curriculum that is appropriate to the community served by the school and for the children in it.

Drawing together connected and complementary knowledge understanding and skills within the areas of learning will enable teachers to design compelling learning experiences that meet the individual needs of children and remove any barriers to learning at that point.

The design framework also contains a simplified framework for the development of personal social and learning skills. These skills are to be taught across the curriculum and the essential knowledge and understanding and skills of citizenship, RE, and PSHE will be set out in the appropriate areas of learning. This will enable all children to understand their approach to learning but will particularly help those with difficulties in this area.

\section{Equality impact assessment}

A positive impact is explicitly intended and very likely.

The new flexible curriculum will allow teachers to tailor learning to all pupils, thus maximising their outcomes.

\section{Next steps}

The new curriculum will promote equality by allowing schools to increase flexibility to tailor learning to their local circumstances and the needs of all children in their care, and promote inclusion, diversity and community cohesion. The QCDA and National College will be developing a support 
package for schools to implement the new primary curriculum. This package will ensure that schools focus on high standards and good progress for all learners, with no child left behind, recognition of the whole child, and the importance of personal development in securing wellbeing and success 


\section{Proposed introduction of statutory Personal, Social, Health and Economic (PSHE) Education}

The policy will ensure that all children receive consistent, high quality PSHE education by making the subject statutory in maintained schools from Key Stages 1 to 4 .

What the evidence shows - key facts

\section{Sexual Orientation}

At schools where children are taught about gay issues and explicitly taught that homophobic bullying is wrong, lesbian and gay pupils are 13 per cent less likely to experience homophobic bullying.

\section{Religion \& Belief}

A 2003 study on Muslim boys and education found that assumptions and stereotypes can have 'real effects and implications for pupils within schools'

\section{Challenges and opportunities}

In terms of equalities issues generally, it is key to note that "Diversity" is a key concept of PSHE education at Key Stages 3 and 4. The Programme of Study requires that students are able to appreciate that, in our communities, there are similarities as well as differences between people of different race, religion, culture, ability or disability, gender, age or sexual orientation, and understanding that all forms of prejudice and discrimination must be challenged at every level in our lives. Through statutory PSHE education therefore, a very real opportunity arises to impact on young people's appreciation of equalities.

More specifically, as evidenced in the evidence chapter, some minority groups experience inequity in the labour market. Effective PSHE education has the potential to develop pupils' communication, decision making, interpersonal and other social skills. Such skills play an important part in success at school and in employment (Feinstein and Duckworth, 2006; Heckman and Rubinstein, 2001; Bowles and Gintis, 2000; Feinstein, 2000; Carneiro, Crawford and Goodman, 2006; Bernard, 2006). PSHE education also covers careers education work related learning and enterprise. PSHE education can therefore help to address disparities in the labour market by ensuring all children have the opportunity to develop such skills.

"Healthy lifestyles" is one of the key concepts of PSHE education at Key Stages 3 and 4 . Students will learn that a person's ability to stay healthy is affected by physical, mental, emotional, social, environmental and economic circumstances. Pupils should learn that they need to make informed decisions about behaviours and consider the short- and long-term consequences of their actions on themselves and others. PSHE education may therefore play 
an important part in reducing health inequalities existing between different ethnic or socio economic groups.

A key challenge will be to ensure that teaching staff responsible for PSHE education are sufficiently equipped to teach high quality PSHE to their students. The Department will be funding Continuing Professional Development (CPD) in PSHE education at a cost of $£ 2$ million per year.

\section{Equality impact assessment}

A positive impact is explicitly intended and very likely.

PSHE education deals specifically with a range of equalities issues as detailed above. The increased consistency with which the subject will be taught following its introduction as a statutory part of the curriculum will contribute to greater understanding by pupils of the important subjects covered.

Strands of study concerning diversity will be statutory for pupils at Key Stages 3 and 4 in 3,383 schools. Whilst it is not currently known exactly to what extent schools do not cover these issues already, research to be commissioned following the consultation will help inform this.

\section{Next steps}

DCSF and QCA will work with equalities stakeholder groups to ensure we address their concerns within the scope of the proposed legislation.

Guidance will reference the links between the PSHE programmes of study and the equalities issues discussed in this assessment and will exemplify for schools how to use PSHE teaching and learning to address these issues. 


\section{Introducing a requirement for teachers to hold a renewable Licence to Practise}

These provisions will introduce a requirement for qualified teachers in maintained schools, non-maintained special schools and academies to hold a renewable Licence to Practise. This will be coupled with a contractual entitlement to continuous professional development (CPD), to be introduced through the School Teachers Pay and Conditions Document, and will build on current performance management arrangements to incentivise teachers to undertake high quality CPD and continuously improve their practice, in order to meet criteria for licence renewal Because teaching quality is the single greatest in-school determinant of pupil outcomes, this will lead to a reduction of in-school and inter-school variation, the narrowing of the attainment gap and improvement in outcomes for pupils across the board.

The overall aim is to support teachers' learning and development to improve teaching quality and thus raise standards and improve outcomes for pupils. The objectives to achieve this are: to increase teachers' access to high quality professional development; to further boost the status of the teaching profession and encourage higher quality entrants; to ensure that all teachers recognise their duty as professionals to keep their skills and knowledge up to date in order to deliver consistently high quality teaching; to guarantee, and provide public reassurance of, professional competence across the teaching profession.

The introduction of a requirement for teachers to hold a renewable Licence to Practise is closely linked with work that the government is taking forward with its social partners on a contractual entitlement to continuing professional development (CPD) for teachers, to be introduced through the School Teachers Pay and Conditions Document.

The White Paper Your child, your schools, our future: building a $21^{\text {st }}$ century schools system, published on 30 June 2009, stated that the Government would introduce a renewable 'licence to teach' (now known as 'licence to practise') alongside continued work on a CPD entitlement. The White Paper set out that "...Our intention is to begin to roll out the new arrangements for qualified teachers and head teachers teaching in maintained schools, nonmaintained special schools and short stay schools (formerly pupil referral units) from September $2010 \ldots$... It specifically stated that “...We envisage beginning roll out with newly qualified teachers and returners to teaching from September 2010 , with supply teachers as soon as is practicable thereafter...". It has also been agreed that the requirement to hold a renewable Licence to Practise will apply to qualified teachers in Academies.

The powers we are taking in the Bill are broad powers around the requirement for qualified teachers to hold a Licence to Practise, the setup of a licensing system to be administered and overseen by the General Teaching Council for England (GTCE), and teachers' right of appeal. The full details of how the licensing system will work have yet to be agreed and will be set out in regulations which will be subject to consultation with the teaching profession 
and other stakeholders. A further equalities impact assessment will take place as these details are worked out. However, the Bill provides that full registration with the GTCE will be a pre-requisite for the award of a licence. Below are outlined some elements of how we currently envisage the system might work, as set out in the policy statements we published in January 2010.

The licensing system will build on the existing processes of statutory induction and performance management for teachers. Once the system has been rolled out to all teachers, we envisage that licence renewal will take place every five years. Newly Qualified Teachers will receive a 'temporary' licence on starting induction, and once induction is successfully completed they will receive a 'full' licence and enter the five year renewal cycle. A 'full' licence will be automatically renewed on the basis of a teacher's preceding five years' performance management reviews provided that none of these show that the teacher is subject to capability arrangements.

In order to ensure the consistency and fairness of the system we currently envisage there will be a local moderation process, which would also be subject to quality assurance.

There will also be an appeals process. We envisage establishing a two tier process - first, the use of local grievance processes; and second, an appeal to the GTCE once the local grievance process is exhausted.

The requirement to hold a licence will apply to returners to teaching and supply teachers but we currently envisage that there are likely to be variations in how the arrangements apply to them. We envisage that these variations will only apply to returners to teaching after a break in service of a certain length this is likely to be at least two years.

We currently envisage that supply teachers who are not subject to statutory performance management arrangements, and returners to teaching after a break in service of at least two years, will be granted a 'temporary' licence until they can demonstrate that they meet the relevant professional standards and have undertaken CPD that has impacted positively on their practice, leading to award of a full licence. For returners, this can be achieved through the performance management arrangements in the same way as other teachers. For supply teachers who are not subject to statutory performance management, we will need to put arrangements in place for them to collect evidence and apply for licence renewal.

Returners to teaching represent excellent value for money in investment terms, since they have already been trained and are rejoining the workforce at comparatively low cost. To support them, the Training and Development Agency for Schools (TDA) commissions Return to Teaching courses to refresh and update their knowledge and skills.

\section{Specific evidence for these provisions}


The most recently available figures show that $74 \%$ of all regular qualified teachers in the maintained schools sector are female. $91 \%$ of part-time teachers are female and $70 \%$ of full-time teachers are female (2008 Database of Teacher Records).

We estimate that just over three quarters of all returners to teaching after a break in service of at least two years, and of all supply teachers, are female. This aligns with the overall percentage of teachers who are female (based on an analysis of the 2007 Database of Teacher Records).

Research commissioned by DCSF through IPSE at London Metropolitan University, covering the period November 2004 to April 2006, found that only $34 \%$ of supply teachers had experienced any CPD throughout 2004 (200809 GTC Annual Digest of Statistics).

\section{Challenges and opportunities}

There is an opportunity for the introduction of a requirement to hold a renewable Licence to Practise, coupled with an entitlement to CPD introduced through the School Teachers Pay and Conditions Document, to bring particular benefit to supply teachers and returners to teaching after a break in service, who are predominantly female.

A teacher who has been away from the classroom for at least two years may not be up to date with the latest developments in pedagogy, for example, which have taken place during that period. And as shown above, supply teachers are much less likely than other teachers to have access to and be undertaking regular CPD. Licence to Practise and the CPD entitlement should together increase access to high quality CPD for both of these groups of teachers, enabling them to keep their skills and knowledge up to date, meet the criteria for licence renewal and continuously improve their teaching practice.

\section{Equality impact assessment}

An adverse impact is unlikely. On the contrary there is potential to reduce barriers and inequalities that currently exist.

For the reasons set out above, the potential to reduce existing barriers and inequalities is due to the likelihood that this policy will bring particular benefit to more women than men (because they are more likely to be supply teachers or 'returners').

\section{Next steps}

Ministers committed in the White Paper Your child, your schools, our future: building a 21st century schools system to developing detailed proposals and consulting with the profession. We consulted informally with key stakeholders including all the social partners at the end of 2009. We aim to publish and formally consult on draft regulations in Spring 2010. 


\section{Elective Home Education}

In June 2009, Graham Badman's Review of Elective Home Education in England identified serious concerns about the constraints that hindered local authorities in identifying whether home educated children were receiving a suitable education: this prevented them discharging their duty to ensure no children in their area were missing education. The policy is a direct response to some of the recommendations arising from the Badman Review.

We propose to strengthen the elective home education framework by introducing a system of registration and monitoring. This will:

- Enable and require all local authorities to identify all electively home educated children in their area and ensure they are receiving a suitable education;

- Support parents to improve the educational outcomes of home educated children;

- Reduce the risk that home educated children can be used to conceal child neglect or abuse.

Affected groups:

The principal minority groups affected by this legislation will be:

Children with Special Educational Needs (SEN);

Children from the Gypsy, Roma and Traveller communities.

\section{What the evidence shows - key facts}

Evidence from the York Consulting Feasibility Study indicated that Children with Special Educational Needs and Children from Gypsy, Roma and Traveller communities were over-represented in the electively home educated (EHE) community.

$16 \%$ of the electively home educated children in the 9 local authorities surveyed were from Gypsy, Roma or Traveller communities; and

$5 \%$ of the children in the 8 local authorities who could provide figures had a statement of special educational needs, compared to $2.9 \%$ of the overall population of children in England in the same year;

Gender distribution in the 9 local authorities sampled was more or less even, and therefore this EqulA does not focus specifically on gender issues.

\section{Challenges and opportunities}


We do not have an accurate picture of the relationship between home education and educational outcomes. The Badman Review identified that little is known about the collective outcomes for home educated children in terms of their qualifications and employment. We aim to address this via an evaluation designed to quantify the impact of the proposed policy on all children, and specifically children from the Special Educational Needs and Gypsy, Roma and Traveller Communities.

We expect Gypsy, Roma and Traveller children to benefit from these proposals but this does not mean that their application will be without challenges. For example, the highly mobile nature of most within these groups may make it more problematic for local authorities to work with them to ensure they benefit from registration and the support the Review recommends. Nevertheless, these communities can expect a net benefit.

\section{Equality impact assessment}

An adverse impact is unlikely, and on the contrary the policy has the clear potential to have a positive impact by reducing and removing barriers and inequalities that currently exist.

The current situation is that there is no requirement for local authorities to keep a register of home educated children and therefore we don't know how many of these children there actually are. Local authorities are aware of about 20,000 children but the figure could be substantially higher.

A recent survey of local authorities found that, in the opinion of officers monitoring home education, around $20 \%$ of children known to local authorities, may be receiving an inadequate education and $1.8 \%$ of children known to local authorities may be receiving no education at all. This means that if there are 20,000 home educated children, 4000 children may be receiving an inadequate education and 360 may be receiving no education at all.

Based on statistics from the York Consulting Feasibility Study the numbers of children from Gypsy, Roma and Traveller background and with SEN within this group are likely to be disproportionately high. Although this policy will not change the overall number or profile of children in elective home education, it will improve local authorities' identification of them and contact with them. So, we would expect them to benefit disproportionately from any benefits generated. 


\section{Next steps}

Registration and Monitoring

The policy allows us, for the first time, to identify accurately all children who are electively home educated. Applications for registration on the home education register will include a statement giving information about a child's prospective education. We envisage that the education statement will contain three types of information:

$\circ$ the educational needs of the child and any relevant background information which affects the way education is structured and delivered. This may, for example, include information about special educational needs or any particular aptitudes the child may have;

○ the educational philosophy or approach to be adopted; and

o outline plans for education in the forthcoming year

Where local authorities have committed to provide support, we would expect this to be detailed in the education plan and for this also to be covered as part of the monitoring discussions,

Monitoring will be carried out informally with an emphasis for the local authority of supporting the home educating family. We envisage that parents and children will describe the education that has taken place during the year, their plans for the following year and discuss with the local authority any support they would like to receive in the short or medium term.

We will consult stakeholders, including those from the third sector, as we develop the details needed for regulations and guidance. Guidance will make it clear that local authorities should act reasonably and consider the families' particular needs and circumstances when setting up monitoring arrangements and this will include consideration of any special educational needs the child may have. The interests of the child are of paramount importance in implementing the registration and monitoring scheme.

We recognise that there may be particularly sensitive issues relating to some children with SEN. In these cases it may not be appropriate for a local authority official to see the child and discussion with other professionals may be the best course of action in addition to receiving written or other reports from parents. It is essential that a multi-agency approach is taken where children have complex needs, and local authorities must be sensitive to the demands made on parents where they have to deal with a range of professionals in relation to the needs of their child.

Our guidance will emphasis that any local authority officer engaged in the monitoring of home education must be appropriately trained so that they understand the diversity of approaches that are taken by home educators and 
are able to make a professional judgement about the education being provided. They will also be appropriately trained in family engagement techniques including speaking to a child and ascertaining the wishes and feelings of that child.

We want local authorities to engage with representatives from all parts of the home educating community in establishing their arrangements for monitoring. Guidance will make it clear too that we expect local authorities to commission support from the private and voluntary sector in monitoring home education, particularly where children have specific needs, or where parents are adopting philosophies where the private/voluntary sector has special expertise.

\section{Support Services}

The identification of all home - educated children, in combination with monitoring visits, is likely to prompt more home educating families to access appropriate support services.

In particular, local authorities have a duty to maintain the statement of SEN in the home, and if local authorities become aware of children with SEN being educated at home about whom they did not previously know, it would be right to expect an improvement in the service offered.

We understand that children with SEN who are home educated face significant challenges in accessing services that are usually accessed through schools. The Review recommendations should allow parents to work through the local authority to gain easier access to these services so that their children are not placed at a disadvantage because they are home educated.

Although not part of our legislative proposals, we have committed to provide funding for a separate package of support for home educating parents, for example, for children with special educational needs; or to allow home educated children to access examination centres, school libraries, or other specialist facilities.

With this in mind, we have already strengthened the Alternative Provision Return guidance to ensure that local authorities know that they can include for Dedicated Support Grant purposes home educated pupils they are supporting financially as a result of a statement, or in respect of significant special needs that have not been formally recognised through a statement.

We will also be introducing, with effect from 2011, a facility for local authorities to claim Dedicated Schools Grant for all home educated pupils accessing school services, but for whom a full unit of grant cannot be claimed because the authority is not giving them substantial support for their Special Educational Needs or because they are attending college. Each pupil accessing these services will be counted as 0.1 of a unit for DSG funding purposes, and we have undertaken to review this level of funding towards the end of the next spending review to assess whether this is an appropriate level. 


\section{New statutory powers to intervene in failing Youth Offending Teams (YOTs)}

These provisions will introduce new statutory powers for the Secretary of State to intervene where an inspection or other evidence reveals a significant failing in a YOT. This will allow the Secretary of State to intervene in cases where identified YOT failings present an immediate risk to the safety of the public or the young people under YOT supervision. In these cases we believe it is necessary for the Secretary of State to intervene directly to maintain confidence in the youth justice system. We therefore plan to legislate for the following powers:

- A general duty for YOTs to co-operate with the YJB - this will give a statutory underpinning to the current improvement process and could be backed up with guidance under 42(3) of the Crime \& Disorder Act which YOT partners shall act in compliance with, either generally or in relation to specific issues at a failing YOT

- Direction making powers so that, for example, if the Secretary of State is satisfied that an Inspection Report or other evidence (e.g serious case review) shows significant failures in the function of a YOT, he can give the YOT such directions that are expedient for the purpose of securing that their functions are performed adequately. (This would direct the particular improvements the Secretary of State would expect the YOT to secure)

- Amending the Crime and Disorder Act so that if the Secretary of State is satisfied that a LA is failing to perform its functions to an adequate standard in relation to creating a YOT, he can give the LA directions for the purpose of securing that the YOT functions are performed adequately (Essentially this would direct the LA on how it exercises its functions to create a YOT. For example require the LA to reconsider how it executes this function having regard to any direction the SoS has made about targets or outcomes required of the YOT and any functions that are or are not to be delegated to the YOT.)

\section{Specific evidence for these provisions}

We have drawn on three key sources - a YJB publication called Differences and Discrimination (Differences or Discrimination? Minority ethnic young people in the youth justice system. Martina Feilzer and Roger Hood in consultation with Marina Fitzgerald and Andrew Roddam; Youth Justice Board 2004), Youth Justice Board Annual Statistics and the equality indicator in the national indicator set related to diversity in the youth justice system. This is NI 44 measure: Percentage point difference in the proportions of each group of young people from minority ethnic backgrounds on youth justice disposals against the proportions of each of these groups in the equivalent local population. 
Also, we have collected and analysed data from a number of quantitative and qualitative sources and drawn on anecdotal evidence.

\section{What the evidence shows - key facts}

The YJB publication Differences and Discrimination looked into whether 'differences in outcome related to ethnicity or gender could be explained in terms of case related or other factors that may be legitimately taken into account; or whether there was evidence that there was any differential, possibly discriminatory treatment.' Conclusions from the study raise concerns about differences that were consistent with discriminatory practice.

The key concerns the Differences and Discrimination study highlights of relevance to proposed new powers to intervene in failing YOTs:

a. The higher rate of prosecution and conviction of mixed parentage young males;

b. The higher proportion of prosecutions involving black young males;

c. The greater proportion of black and Asian males that had been remanded in custody before sentence, especially the greater proportion of black males remanded whose proceedings had not resulted in a conviction;

d. The slightly greater use of custody for Asian males;

e. The greater use of more restrictive community penalties for Asian and mixed parentage males, especially those aged 12 to 15;

f. A greater likelihood that black and Asian males aged 12 to 15 would, if they received one of the more restrictive type of community sentences, be under supervision for longer than 12 months;

g. A slightly greater propensity for ethnic minorities to have been committed to the Crown Court;

h. The much greater proportion of mixed parentage females who were prosecuted;

i. The substantial variations in outcomes between YOT areas; and

j. A much greater probability that a black male, would, if convicted at a Crown Court, receive a sentence of 12 months or longer.

\section{Youth Justice Board Statistics}

The Youth Justice Board Annual Statistics include national figures on youth justice disposals given to young people in the period 2007/2008. These are broken down into age, gender and ethnicity. The statistics are available on the YJB website which can be found at www.yjb.gov.uk.

There is a diversity indicator in the national indicator set related to diversity in the youth justice system. This is NI 44 measure: Percentage point difference in the proportions of each group of young people from minority ethnic backgrounds on youth justice disposals against the proportions of each of these groups in the equivalent local population. 
Youth Justice Board's annual statistics show that nationally, the black ethnic group is the most over represented ethnic group in the youth justice system. Black young people account for $2.9 \%$ of the $10-17$ year old general population, but $5.9 \%$ of the $10-17$ year old offending population.

Asian young people are the most under represented in the youth justice system. Asian young people account for $6.1 \%$ of the $10-17$ year old general population compared to $3.6 \%$ of the young offender population.

Mixed background young people were also over represented. They accounted for $2.9 \%$ of the $10-17$ year old population compared to $3.1 \%$ of the young offender population.

\section{Consultation and Involvement}

\section{Stakeholder/community involvement in developing proposals}

As part of the Youth Crime Action Plan (YCAP) we consulted on a whole range of measures which would contribute to reducing offending and reoffending by young people. Part of this consultation looked at how we performance manage YOTs to ensure that they are contributing to our strategic objectives. This was a wide ranging consultation both in the drafting of the Action Plan and following its publication.

An array of stakeholders, delivery partners and other Government Departments have been involved in YCAP and have had the opportunity to influence policy as it has progressed. Respondents to the YCAP consultation included the Equality and Human Rights Commission, Council for Disabled Children, Health and Wellbeing and the Childhood Bereavement Network. We also received responses from a wide range of other children's and penal stakeholders. The majority of respondents were in favour of the measures set out in YCAP. Most welcomed the emphasis on improving the performance of YOTs and using this as a lever to ensure that all young people under YOT supervision receive the support and access to services they need to help prevent offending behaviour becoming entrenched. Equalities respondents did highlight the need to ensure that specific equality issues were addressed in taking forward YCAP policies.

Furthermore we have undertaken a short canvassing of views from stakeholders and delivery partners on these specific powers. We have also met with a range of organisations who have an interest, including the devolved administrations. The majority of organisations have indicated that they are content with the powers and acknowledged that the powers filled a gap in the current performance management process where failings were the most serious or severe. We acknowledge that some of our delivery partners would like to see these powers clearly linked to the current performance management framework and are keen to ensure that they are only used as a last resort. We will continue to work with stakeholders to address any issues they may have. 


\section{Challenges and opportunities}

These powers will help us keep track of how YOTs are performing against local performance indicators including those related to diversity. Where significant YOT failings are identified we could use the powers to intervene to ensure that key performance measures are maintained.

The proposed new powers have the potential to have a positive impact on all young people regardless of ethnicity, gender or disability. The focus is on improving YOT's performance where failings and weak performance have been identified through direct intervention from the Secretary of State. This could be used where identified failings relate to specific equality issues. We believe that these powers will ensure that young all young people, receiving YOT supervision receive a high quality service tailored to their needs which will help to address their offending behaviour and turn them away from entrenched offending behaviour.

These powers have the potential to present an opportunity to improve equality issues within the youth justice system by providing a formal backstop provision to intervene where serious YOT failings have been identified. We envisage that the power would be used where YOT failings present an immediate risk of serious harm to either the young people under YOT supervision or the safety of the general public. This will benefit all young offenders by ensuring they have an appropriate level of service. It also means that there are formal powers to intervene where serious failings relate directly to issues of equality. The ability to intervene and rectify any failings of this type will have positive outcome for all young offenders.

\section{Equality impact assessment}

A positive impact is explicitly intended and very likely.

This is because these powers could be used to address inequality directly, since they could be used if major failings in equality are discovered or indeed if YOTs are failing to meet equality targets and/or performance indicators.

\section{Next steps}

The key objectives of this assessment have been to consider whether the proposal is correcting current inequalities, introducing inequalities that might be justified or considering whether the policy will be equality neutral in effect.

There were a number of key concerns evident in the Differences and Discrimination publication that raise concerns about perceived current inequalities in the youth justice system. Correcting these inequalities prior to the proposed new statutory powers is improbable as the relationship between ethnicity and offending level is multifaceted and there is no quick fix solution. While the extent of the cause of such complexities is not addressed directly in the Differences and Discrimination study the research identifies concerns which serve to reinforce the widely held belief that there is a known lack of 
confidence and higher levels of distrust amongst black and minority ethnic groups who come into contact with the criminal justice system.

As set out above, these legislative changes are aimed to cater for everyone in the youth justice system and the issues of inequality in relation to ethnicity, gender and age are all considered. The proposed statutory powers will provide legal basis for the Secretary of State to intervene from the centre where an individual YOT is failing in its duties, or if there is a significant YOT failure that needs urgent solution. The action that the Secretary of State will take to rectify these failures will benefit young offenders who will have been affected by such failures. In fact, a YOT's failure would mean failing all those who receive services from that particular YOT, including young offenders from ethnic minorities, female offenders, disabled young offenders and other minorities. And rectifying these failures will obviously have positive outcome for all young offenders.

We believe that these powers are required as a safety net where serious failings present a clear and present danger to young people or the safety of the public and where intervention is required quickly and robustly. The Government's view is that possible triggers for these interventions could be a YOT inspection that shows serious and systemic failures within the YOT organisation that are clearly impacting on the performance of the YOT, its duties to care for the young people under their supervision and wider public protection responsibilities. This could include failure to adhere to equalities legislation or other failings related to equality as well as failings which could put the young people supervised by the YOT at risk of serious harm. Or where there is other evidence of significant YOT failings in the supervision or support offered to the young person which may necessitate a timely and robust response to ensure that public safety is not compromised. There may be other instances or examples which will need to be judged on a case by case basis.

\section{Post Implementation Review}

We will need to review the nature and use of these powers to ensure that they are used appropriately. We intend that voluntary co-operation between the YOT and the YJB should remain the normal way of securing performance improvement with the power to co-operate being used only where voluntary engagement is proving problematic.

Ultimately the powers for the Secretary of State to direct improvement or to direct the LA in the performance of its function to establish a YOT will only be used in extremis where failings are so serious that they present a clear and present danger to young people or the safety of the public. In this context the use of these intervention powers should be reviewed on each occasion they are used. In practice this will happen as a matter of course as we will need to know whether appropriate performance improvements have been put in place post intervention. We will also review the effect of the intervention and the process by which any failings were identified and the role of the centre in initiating the powers to ensure that they are used proportionately 
We shall continue to monitor the impact of our proposals across the three equality strands discussed here. 


\section{Equality Impact Assessment Initial Screening - Relevance to Equality Duties FAMILY COURTS}

\section{Name of the proposed new or changed legislation, policy, strategy, project or service being assessed:}

Legislative Reform to Reporting Restrictions Governing Family Courts
This legislation is needed to continue the process of reform to make family courts more open. It will broaden the amount of information which
can be reported by those media representatives attending proceedings, through a staged process, subject to an independent review following
the introduction of the first stage. The legislation will build on new rules of court which came into force on 27 April 2009 , which for the first
time gave accredited members of the media the right to attend most family proceedings in the county courts and High Court. The media
attendance rules were achieved through secondary legislation however Primary legislation is needed to give effect to a clearer and more
consistent reporting restriction framework across all tiers of family court. The Government's decision to revise the current statutory framework
governing the reporting of family cases was announced in the Draft Legislative Programme for $2009 / 2010$ on 29 June 2009 . The new
proposed legislative framework will allow for greater reporting of family proceedings, while protecting the privacy of the children and families
involved. These provisions will form part of the Children, Schools and Families Bill. This EIA looks at the likely Equality Impacts of the
proposed legislative changes.

\section{Individual officer(s) \& Unit responsible for completing the Equality Impact Assessment:}

Misto Miah Chowdhury, Erika Maass - Ministry of Justice, Family Law \& Justice Division

3. What is the main aim or purpose of the proposed new or changed legislation, policy, strategy, project or service and what are the intended outcomes?

\begin{abstract}
Aims/objectives
To revise the current legislative framework governing the reporting of family cases so that the media can report more widely to the public on how the courts make difficult decisions. The media will also provide independent scrutiny of family court decisions, increasing public confidence in these proceedings.

To create a comprehensive and consistent set of reporting restrictions governing all tiers of court and most types of family proceedings.
\end{abstract}

Outcomes

To deliver a more effective, transparent and accountable family justice system. This includes increased public confidence in the family justice system; giving vulnerable adults and children the best possible protection; a more consistent, comprehensive and transparent statutory framework governing the reporting of family cases; significantly improving the visibility of justice for families who receive it from a reformed justice system; providing accredited members of the media the ability to be able to report more widely about the proceedings they attend, but at the same time increasing the protection for those involved by providing life long anonymity for the adults and parties involved. 
Reviews of existing internal and external evidence were conducted as part of the evidence gathering process. A public consultation was conducted by the MoJ in 2006 and then again 2007, which asked questions on reporting restrictions generally. The "Confidence and confidentiality: improving transparency and privacy in family courts" consultation paper was published on 11 July 2006 and put forward a number of proposals with the aim of improving public confidence in the family courts, whilst continuing to safeguard the privacy of those involved in proceedings. The consultation elicited 245 formal responses from individuals and organisations which provided a diverse range of views on reporting restrictions. In addition, consultation with a comprehensive range of stakeholders was achieved by a series of MoJ events that gave people the opportunity to debate the proposals, including an online forum for children and adults. An overview of the consultation responses was published on $22 \mathrm{March}$. Notes of the stakeholder events are published in the response to the consultation. We have used feedback from the consultation responses to help us identify the likely impact on different groups.

External research which has been taken into consideration includes:

* Minority ethnic parents, their solicitors and child protection litigation, By Julia Brophy, Jagbir Jhutti-Johal, Eleanor McDonald, Oxford Centre for Family Law and Policy, University of Oxford.

* Brophy J (2003b) Diversity and child protection, Family Law, September, pp 674-678.

* Brophy J (2000) 'Race' and Ethnicity in Public Law proceedings, Family, pp 740.

* Brophy J, Jhutti-Johal J, Owen C (2003a) Significant Harm: Child Protection Litigation in a Multi-cultural

* Dr Tahir Abbas, 'Race, Ethnicity and the Courts: a review of existing and ongoing research.

\section{Are there gaps in information that make it difficult or impossible to form an opinion on how your proposals might affect different groups of people? If so what are the gaps in the information and how and when do you plan to collect additional information?}

Ethnic minorities within the civil justice system are particularly under-researched (Tahir 2004). In family cases the courts currently only record personal information such as date of birth, financial details and the presence of the child so it is difficult to obtain any quantitative data on the number of litigants who are from an ethnic minority or any data on gender. This clearly makes it difficult to understand whether any groups are over or under represented in family proceedings and therefore would be disproportionately affected by the legislation. Changing the current family court forms to record ethnicity, gender and disability will involve a disproportionate cost being incurred by the department. However when the SUPS computer upgrade takes place in 2011, it is anticipated that this information will be collected. Also there is no reliable evidence on access to the family courts by disability or transgender groups, which is why as part of our stakeholder handling strategy we have met with key stakeholder groups including those representing the gay community, faith groups, disability representative groups and trans-gender organisations to better understand any likely impacts. The meetings provided assurance that these groups were satisfied that protections such as lifelong anonymity for the families involved, the automatic restriction on publication of sensitive personal information and the right of parties to apply to restrict publication of information were sufficient to ally any concerns. 


\section{Having analysed the initial and additional sources of information including feedback from consultation, is there any evidence that the proposed changes will have a positive impact on any of these different groups of people and/or promote equality of opportunity?}

Yes. Overall, it is more likely that impact of the legislative changes will be positive rather than negative. It should also be noted that many families actively want publicity for their case in order to expose what they perceive as important failings in the justice system and in the public child care system (Webster's case). The policy will have a beneficial impact on fathers groups who have long campaigned that 'secret' family courts are biased against fathers when it comes to contact and residence cases. The policy is responding to growing calls for more transparency in the family court from members of the public, MPs, judges and others. This legislation will make the family courts more open and satisfy the legitimate public interest that exists. The proposals will also benefit the public in general, as the current arrangements make it very difficult for the public to understand how the family justice system works and how family courts make their decisions. Press attendance and allowing the media to report more widely will help more people understand how the family justice system works and provide independent scrutiny of the decisions of the court. works This scrutiny of the family courts will in turn lead to a more effective service which will benefit both the children involved in the court process and their families.

\section{Is there any feedback or evidence that additional work could be done to promote equality of opportunity?}

It was recognised that there was a need to gather further information to understand the impact of the legislation on particular groups. Consultation with a diverse range of interests groups including those representing the gay, transgender, faith and disability communities has provided assurance that the impact of the legislation will be minimal. The Bill provisions provide a wide range of automatic protections and discretionary powers of the court to ensure that the privacy of those involved in proceedings is protected, in a non discriminatory way.

\section{Is there any evidence that proposed changes will have an adverse equality impact on any of these different groups of people?}

Please provide details of who the proposals affect what the adverse impacts are and the evidence and analysis used to identify them.

Some equality impact issues were raised by the respondents to the first consultation on the reforms in 2006 . These are summarised below:

What issues were raised by the different groups?

CAFCASS (Response, 2006) were particularly concerned that children from some BME backgrounds would feel a greater sense of familial shame than the wider population, particularly if there were 'media sensationalism' or 'simplistic analysis' of a case. 
Inspire, Black Country: This organisation submitted the findings of a relatively small research project as their response to the consultation. The qualitative research explored the views of women, particularly those from BME backgrounds, on the consultation proposals. While none of their respondents agreed that the media 'should be present at family court cases', due mostly to a 'serious concern about irresponsible reporting', one respondent felt that 'Asian women in particular would retract their case knowing that the media would be present for fear of alienation from the community'.

Association of Lawyers for Children: Courts should consider 'where confidential information is involved and others attending would damage their confidentiality' in deciding what additional reporting restrictions to impose.

Rights of Women, Response 2006 There should be strict reporting restrictions placed on the media attending family proceedings. Reporting restrictions should provide for anonymity for both adults and children involved in family proceedings and should prevent the identification of information which is intended, or likely, to indentify a child or adult involved in family proceedings. Comprehensive rules need to be set our regarding what can and can't be reported

Welsh Women's Aid, Response 2006: It is important that all parties to proceedings remain anonymous because children can be identified through their parents. All should be anonymous unless the parties to the proceedings consent for them to be identified. This recommendation will ensure that all parties are comfortable with how the case is going to progress and what information will be in the public domain. This will hopefully ensure that people do not feel inhibited when giving intimate evidence in court. It is important to highlight within this context the impact on certain minority ethnic children and parents

\section{How the MoJ will address these concerns}

The issues identified by consultees above and others have been taken into consideration in developing the proposals being taken forward in the Bill. For example in order to mitigate the risk of 'jigsaw identification' the Government has included a strict ban on publishing information which is likely to lead members of the public to identify the individual as someone who is or has been involved in proceedings. This is a strengthening of the current legislative position. The proposed legislation contains a number of safeguards which aim to respect the rights of parties, witnesses and children under Article 8 of the European Convention on Human Rights. It is submitted that these safeguards would in any event provide sufficient protection regarding privacy of the information in the proceedings. Where the court is required to make a decision, it will always do so in the light of representations from those affected and on the individual facts of each case.

\section{Key provisions in the Bill which will mitigate any adverse equality impacts.}

- The automatic restriction on reporting of any information which identifies, or is likely to identify an individual involved in relevant family proceedings. This would include parties, witnesses and children, although not professional witnesses. This prohibits not only reporting of names, addresses, and schools of those concerned, but also other information which, alone or in combination with other facts, would be likely to reveal the identity of a protected person. Responding to concerns raised during the Commons public evidence sessions, the Government has brought forward a Government amendment which will add a list of restricted categories of information that may lead to identification to make it clearer to judges and reporters as to what information can be reported. This restriction on reporting identification information is indefinite and is a strengthening of the current position.. It may be relaxed or lifted 
by a court, but a court would hear representations from those affected before making such a decision, and would apply the provisions of the Human Rights Act in so doing.

- The starting point for the legislation will be the publication of "sensitive personal information", which includes medical and health matters and disclosures by children, will be prohibited unless the court gives specific permission. In taking a decision to allow the publication of sensitive personal information the court will hear representations from those affected, and will have to apply the provisions of the Human Rights Act in so doing.

- Discretionary powers of court to impose additional reporting restrictions where it is satisfied that publication would prejudice the welfare of a child, the safety of a vulnerable person or in the interests of justice.

- Parental order and adoption information will automatically be excluded from being published

-Current rules of court permit the court of its own motion or on the application of the parties to exclude media representatives for the whole, or part of a hearing where necessary. Grounds for exclusion include where it is in the interests of a child, for the safety and protection of a party, witness or person connected with such party or witness, or where justice will be impeded or prejudiced.

These provisions ensure that all of the equality impacts identified are satisfactorily addressed.

\section{Is there any evidence that the proposed changes have no equality impacts?}

\section{Please provide details of the evidence and analysis used to reach the conclusion that the proposed changes have no} impact on any of these different groups of people.

There are potential equality impacts which we have briefly outlined above, however we have taken steps to ensure that safeguards are included in the proposed legislation to address and mitigate some of the issues that have been raised by the respondents, and to make sure that no particular group or faith is disproportionately affected by the policy.

10. Is a full Equality Impact Assessment Required? (If no, please explain why not)

\section{No}

A full equality impact assessment is not required, as the proposals will not disproportionately affect any particular group or individual. This is supported by the research and evidence gained from directly engaging in consultation with relevant stakeholders.. 
11. If a full EIA is not required, you are legally required to monitor and review the proposed changes after implementation to check they work as planned and to screen for unexpected equality impacts. Please provide details of how you will monitor evaluate or review your proposals and when the review will take place.

The Ministry of Justice intends to monitor the operation of the law following implementation. Ongoing monitoring of the reforms can be achieved by-

- Intermittent searches of any new case law relating to reporting of family cases;

- $\quad$ reviewing professional commentary on reforms; and

- reviewing academic commentary on reforms.

The Ministry of Justice will as part of the post legislative scrutiny process submit a memorandum to the relevant select committee, which will include a preliminary assessment of how the Act has worked out in practice, relative to objectives and benchmarks identified during the passage of the Bill.

There will also be an independent review of the operation of the legislation, no sooner than 18 months from commencement of the legislation, should the Lord Chancellor decide to use his power to move to a more open second stage where only identification information is barred from being published without the court's permission. Such a review will include a public consultation and will give consideration to the impact on particular groups and children and their families. Further scrutiny measures include a report setting out the conclusions of the review and any move to the second more open phase will be subject to the affirmative resolution of both Houses of Parliament.

\section{Name of Senior Manager and date approved}

You should now complete a brief summary (if possible, in less than 50 words) setting out which policy, legislation or service the EIA relates to, how you assessed it, a summary of the results of consultation a summary of the impacts (positive and negative) and, any decisions made, actions taken or improvements implemented as a result of the EIA, including the review mechanism. The summary will be published on the external MoJ website.

Not applicable

Name (must be grade 5 or above): Nick Goodwin

Department: Ministry of Justice - Family Law \& Justice Division

Date: Feb 2010 


\section{ANNEX 1 Relevant Literature}

The following sources are drawn upon throughout this Equalities Impact Assessment:

- DSCF Record of Monitoring Evidence Advice Note 05/08 March 2008, and QCA Single Equalities Scheme

\section{Schools - general}

- Deprivation and Education: the evidence on pupils in England, Foundation Stage to Key Stage 4; March 2009

- DCSF: Attainment by Pupil Characteristics, in England 2007/08 (http://www.dcsf.gov.uk/rsgateway/DB/SFR/s000822/index.shtml)

- Statistical First Release: National Curriculum Assessment, GCSE and Equivalent Attainment and Post-16 Attainment by Pupil Characteristics in England 2005/06 (Provisional) (SFR 46/2006)

- Gender and Education: the evidence on pupils in England (DfES 2004)

- Gender and Education DfES 2007

- Youth Cohort Study (YCS), Ethnicity and Education: The Evidence on Minority Ethnic Pupils (DfES 2004),

- DCSF Research Report 843: An Investigation of Personalised Learning Approaches used by Schools; 2007 (DCSF RR843, 2007).

- General Teaching Council advice to Government and response to the 2020 Vision report; April 2007.

\section{Exclusions}

- DCSF Statistical First Release18/2009: Permanent And Fixed Period Exclusions From Schools And Exclusion Appeals In England, 2007/08; 30 July 2009

\section{Disability}

- Disabled parents' involvement in their children's education: an examination of good practice (Roseann Maguire, Richard Brunner, Kirsten Stalker, June Mitchell Department of Educational and Professional Studies, University of Strathclyde) published 1/10/09

- Literature Review by the Disability Rights Commission, 2005;

\section{Parental involvement}

- The Impact of Parental Involvement on Children's Education, DCSF-00924-2008 (2008)

- Gutman, L.M. and Akerman, R. (2008). Determinants of Aspirations. Centre for Research on the Wider Benefits of Learning Research Report 27. London. Institute of Education.

- Peters, M., Seeds, K., Goldstein, A. and Coleman, N. (2008) Parental Involvement in Children's Education 2007. Research Report. DCSF RR034. 
- The National Survey of Parents and Children: Family Life, Aspirations and Engagement with Learning (DCSF 2007074, October 2008)

- Harris, A. and Goodall, J (2007). Engaging Parents in Raising Achievement - Do Parents Know they Matter? DCSF Research Report. RW 004.

- Goldman, R (2005). Fathers' Involvement in their Children's Education. London: National Family and Parenting Institute.

- Desforges,C. and Abouchaar, A. (2003) The Impact of Parental Involvement, Parental Support and Family Education on Pupil Achievement and Adjustment: A Literature Review. DfES Research Report 433.

- O'Brien, M. and Shemilt, I (2003). Working fathers: Earning and caring. Manchester: Equal Opportunities Commission.

- Barn, R., Ladino, C. and Rogers, B. (2006) Parenting in multi-racial Britain. Parenting in Practice series National Children's Bureau.

\section{Parental Responsiveness}

- Ofsted surveys

- recent department parent surveys to support LA commissioning

- LA Commissioning Pathfinders National Survey.

- DCSF SSA01/2008

- 'Learning from experience: schools commissioning by local authorities' (2008), DCSF

\section{Extended Schools}

- Extended Schools Survey of Schools, Pupils and Parents (Wallace, Smith et al; 2009)

- Evaluation of the Full Service Extended Schools Initiative (Cummings, Dyson et al; 2007). The Full Service Extended Schools (FSES) initiative was a group of full service extended schools which acted as 'pathfinders'. DFEE Schools Plus: Building Learning Communities (1999)

\section{SIPs}

- National Strategies and DCSF internal review of SIPs (2009)

- The New Relationship with Schools (NRwS) Evaluation, carried out by York Consulting for DCSF (Published August 2008)

- Cambridge University evaluation of the special SIP pilot (2006)

- York consulting Ltd evaluation of the Primary pilot (2006)

- NFER evaluation of the NRwS trial (2004)

\section{School Report Card}

- 21st Century Schools evidence narrative and evidence base for the White Paper

- 21st Century Schools: A World Class Education for Every Child 
- A School Report Card: consultation document Analysis of responses to the Consultation documents: Consultation Unit, DCSF June 2009

- School Accountability and School Report Cards CPR1170 DCSF and COI communications November 2008

These are public documents and are available at www.dcsf.gov.uk/21stcenturyschoolsystem

\section{PSHE}

- Ofsted 2005a "Personal, social and health education in secondary schools"

- Ofsted 2007 "Time for change? Personal, social and health education"

\section{Home Education}

- The Prevalence of Home Education in England: A Feasibility Study, York Consulting for DCSF, December 2006;

- The Review of Elective Home Education in England: Badman July 2009

\section{Special Educational Needs}

- Annual publication by DCSF:DCSF Statistical First Release Special Educational Needs in England

- Annual reports published by the Tribunals Service, First-tier Tribunal - Health, Education and Social Care Chamber, Special Educational Needs and Disability

- Special educational needs and ethnicity: issues of over and under-representation (Geoff Lindsay et al, University of Warwick, RR757, May 2006)

\section{SEN Inspection}

- The framework for school inspection in England under section 5 of the Education Act 2005, from September 2009 and the evaluation schedule for schools, both of which are accessible from Ofsted's website set out the inspection arrangements and judgements made.(www.ofsted.gov.uk).

- Inspection, accountability and school improvement, report of the Lamb Inquiry to the Secretary of State, published 3 August 2009. 